\title{
Assessing the Stabilizing Effects of Development Programming: A Review of USAID's Evaluation Efforts in Afghanistan
}

Daniel Egel and Peter Glick

RAND NDRI

WR-1106-MSI

June 2016

Prepared for Management Systems International (MSI)

RAND working papers are intended to share researchers' latest findings. Although this working paper has been peer reviewed and approved for circulation by the International Security and Defense Policy Center of the RAND National Security Research Division, the research should be treated as a work in progress. Unless otherwise indicated, working papers can be quoted and cited without permission of the author, provided the source is clearly referred to as a working paper. RAND's publications do not necessarily reflect the opinions of its research clients and sponsors. RAND® is a registered trademark. 


\section{Preface}

This report reviews the methodology and tools developed by the Measuring Impact of Stabilization Initiative (MISTI) to assess the impact of United States Agency for International Development (USAID) stabilization-focused programming in Afghanistan. We identify strengths and limitations of the MISTI approach, and identify recommendations for improvement. In addition to providing structured feedback to MISTI to enhance future analyses in Afghanistan, the intent of this report is to use the MISTI evaluation to illustrate the types of challenges faced in evaluating stabilization-focused interventions. Therefore this review should be of interest to researchers and policymakers planning or conducting experimental or quasi-experimental impact evaluation in conflict settings.

This research was conducted within the International Security and Defense Policy Center of the RAND National Security Research Division (NSRD). NSRD conducts research and analysis on defense and national security topics for the U.S. and allied defense, foreign policy, homeland security, and intelligence communities and foundations and other nongovernmental organizations that support defense and national security analysis. Management Systems International (MSI) provided funding for this research.

For more information on the International Security and Defense Policy Center, see http://www.rand.org/nsrd/ndri/centers/isdp.html or contact the director (contact information is provided on the web page). 


\section{Table of Contents}

Preface

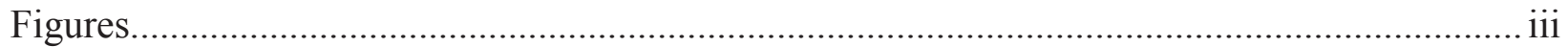

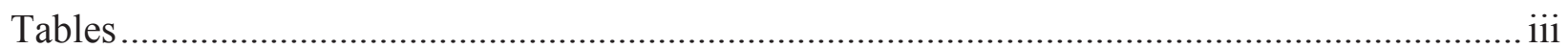

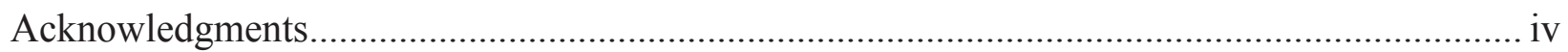

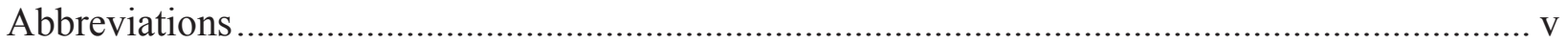

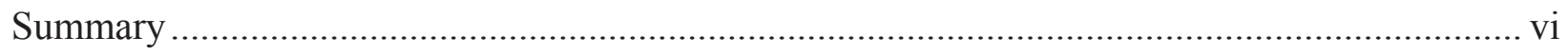

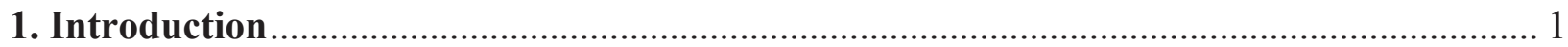

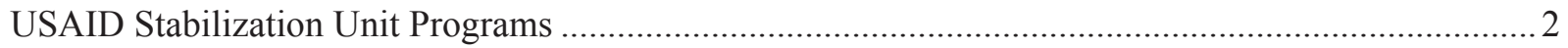

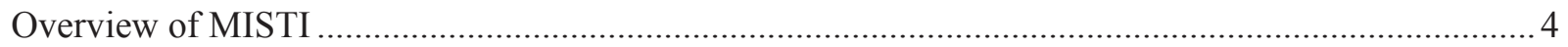

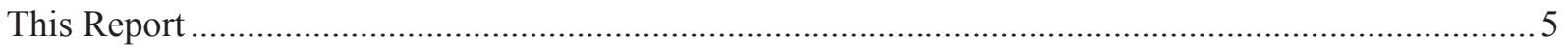

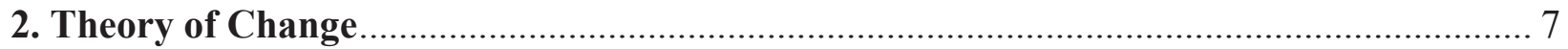

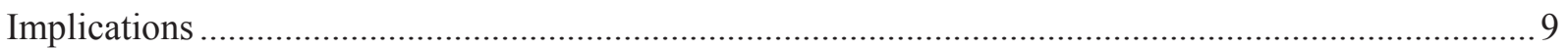

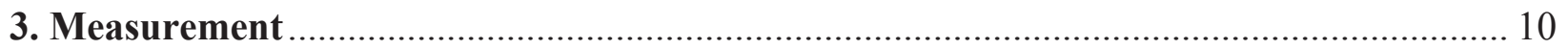

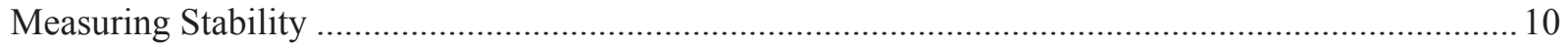

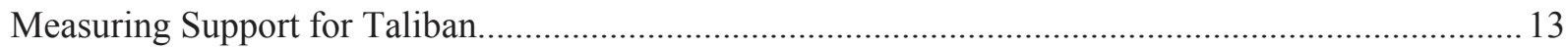

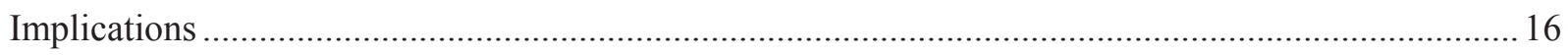

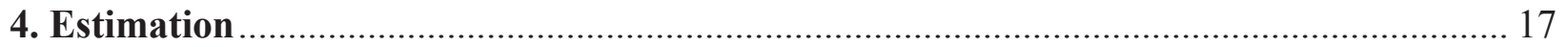

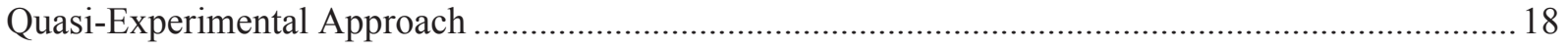

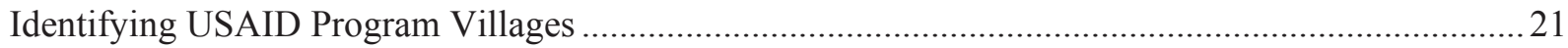

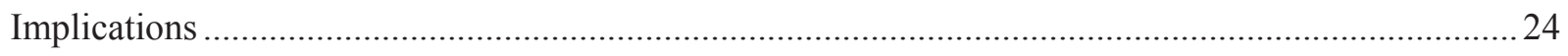

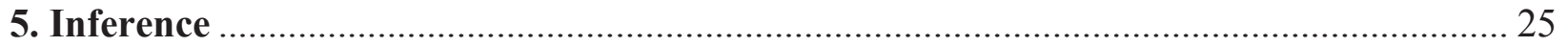

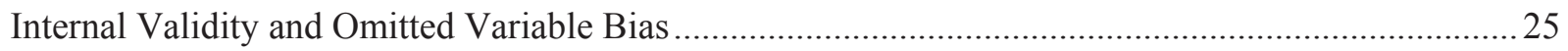

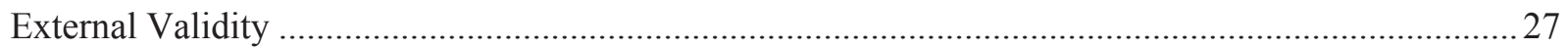

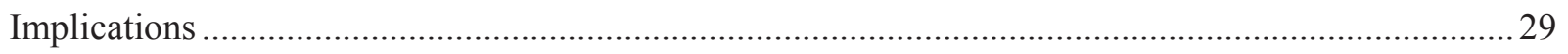

6. Implications for MISTI and Assessment in Conflict Settings …................................. 31

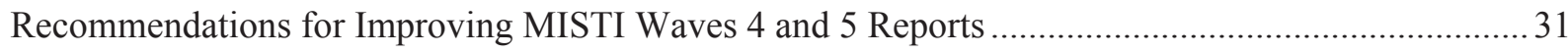

Things that Could Have Been Done and Should be Done for Future Evaluations............................... 34

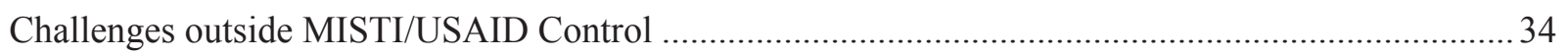

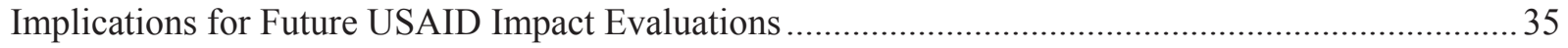

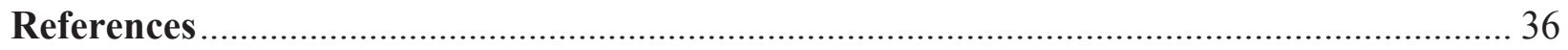




\section{Figures}

Figure 1.1: USAID Stabilization Unit Programming during 2012-2015 ................................. 2

Figure 4.1: Comparing Treated and Control Villages ........................................................ 20

Figure 5.1: Comparing Wave 1 to Wave $1 \& 3$ Panel ............................................................... 29

\section{Tables}

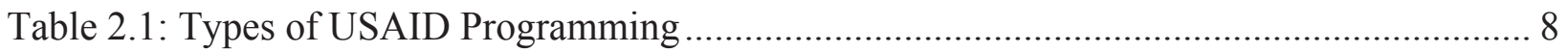

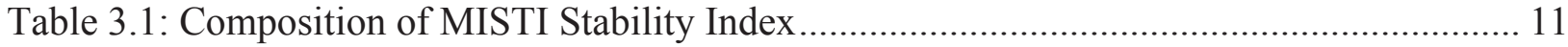

Table 3.2: Questions for Endorsement Experiment ...................................................... 14

Table 3.3: Correlation among Endorsement Experiment Questions ....................................... 15

Table 4.1: Summary Statistics for Potential Project Misclassification....................................... 23

Table 5.1: Overlap Across Available Survey Data ............................................................... 28 


\section{Acknowledgments}

The authors gratefully acknowledge the support of personnel from the Measuring Impact of Stabilization Initiative (MISTI) team that supported this review. They made themselves, their data, and draft reports available for this analysis, which greatly enhanced the depth of the analysis that we were able to conduct. The MISTI team also provided useful feedback to a fall 2014 draft of this report. We thank Dr. Alex Rothenberg who provided excellent comments on a draft version of this report. 


\section{Abbreviations}

ACSOR

ANDSF

CCI

IDLG

ISAF

KFZ

MISTI

MRRD

NSP

SIKA

USAID
Afghan Center for Socioeconomic and Opinion Research

Afghan National Defense and Security Forces

Community Cohesion Initiative

Independent Directorate of Local Governance

International Security Assistance Force

Kandahar Food Zone

Measuring Impact of Stabilization Initiative

Ministry of Rural Rehabilitation and Development

National Solidarity Program

Stabilization in Key Areas

United States Agency for International Development 


\section{Summary}

In 2010, the United States Agency for International Development (USAID) formed the Afghanistan Stabilization Unit in order to coordinate all USAID activities with the U.S. military, other international actors, and the Government of the Islamic Republic of Afghanistan. Initially focused on supporting the military-led counterinsurgency strategy, in 2012 the Afghanistan Stabilization Unit shifted efforts toward "reinforcing the legitimacy of the government and its effectiveness at the subnational and community levels, and improving communities' resilience to malign, antigovernment actors", or broadly speaking, 'stability'.

This review assesses the methodology and tools used to evaluate the impact of USAID programming, executed during 2012-2015 under the auspices of the Afghan Stabilization Unit, on perceptions of stability. The purpose is to identify strengths, limitations, and recommendations for improvement of this approach, which was developed and implemented by the Measuring Impact of Stabilization Initiative (MISTI). In addition to providing structured feedback to MISTI to enhance future analyses in Afghanistan, this study uses the case of MISTI to illustrate the types of challenges faced in evaluating stabilization-focused interventions. To carry out this review, we analyzed MISTI reports and available data, surveyed relevant academic research, and conducted interviews with relevant USAID program officers and MISTI personnel and sub-contractors involved with the collection, analysis, and synthesis of data.

Several key overall findings emerge from our review. First, the MISTI data collection and analysis can provide an effective tool for measuring the direct impacts of USAID programming conducted during 2012-2015, meaning the impacts for which these programs were originally designed. That is to say, with the tools at hand, MISTI should be able to provide credible estimates of governance programs on governance outcomes, economic programs on economic outcomes, etc. Although the evaluation approach presented in existing MISTI reports has several empirical limitations, most are surmountable given the range and quality of data collected, making a credible impact evaluation of direct program impacts feasible.

Second, though the MISTI evaluation is well-designed to measure these direct effects, it is less clear whether MISTI can provide credible estimates of the indirect impact of USAID programming on stability. Stability is in fact the focus of the MISTI evaluation. However, it is only an indirect potential outcome of the various programs put into place. And as the USAID programming was implemented without a clearly delineated theory of change, i.e., how the diverse types of programming would ultimately impact stability, analyses of the relationships between this programming and stability are difficult to interpret. Indeed, each of these different

${ }^{1}$ USAID (2013a, p. 2). 
types of programs would be anticipated to impact stability through different pathways and over different timelines.

Further, as it is currently constructed, the primary tool used to measure stability - the stability index - is unlikely to be adequate for this purpose. It is not clearly defined, combining fairly disparate elements which do not add up to a clear construct for 'stability'; it is unlikely that a single 'stability' construct exists, so it is not clear what the index actually measures. Further, the weighting of the elements of the index is based on the judgements of the MISTI team hence is bound to be somewhat arbitrary, whereas data-driven approaches are more common and would be sounder. To measure support for the Taliban vs. the government, the evaluation also used an endorsement experiment, which measures Taliban support using subtle word variation across surveys. While the findings using the endorsement experiment appear internally consistent, given the context we recommend that additional ancillary data be employed to validate that the approach is measuring what it aims to.

Third, a key lesson learned from this evaluation - and a more general one - is the importance of external coordination in planning and carrying out an impact evaluation in an unstable, conflict context like Afghanistan. This would involve, most importantly, close coordination with the implementing partners and other development, security, and international organizations. This coordination would mean that evaluators and implementers are in communication to ensure, for example, that unambiguous data on program location and the theories of change underlying the efforts of the implementing partners are available to evaluators. Doing so involves additional time, effort, and resources for the implementing partners, but the cost is reasonable relative to the benefits, as well as to (in this case at least) the enormous level of resources devoted to providing the programs. As this review shows, the lack of such coordination has been particularly problematic for the MISTI evaluation.

Our review also produces the following recommendations for improving future iterations of MISTI analysis as well as future experimental and quasi-experimental impact evaluation efforts in conflict settings:

\section{$>$ Recommendations for Improving MISTI Waves 4 and 5 Reports}

1. Assess severity of treatment/control misspecification by augmenting existing MISTI validation effort with a village- or district-level survey module during Wave 5 data collection.

2. Report results using a variety of quasi-experimental matching methods to verify the robustness of the findings.

3. Work with implementing partners to identify how villages were selected for program participation.

4. Include expanded data and project-specific variables on development programming as control variables in the empirical analysis.

5. Use data-driven methods for deriving the requisite stability index. 
6. Analyze individual or groups of components of stability separately for the impact evaluation.

7. Validate the stability measure using historical polling data and violence data.

8. Coordinate with ISAF and other representatives to validate the stability metric.

9. Rather than focus on only the reduced form outcomes currently considered-i.e., from program inputs to stability - the analysis should also evaluate whether the program is having the intended immediate impact (e.g., improved district governance) as well.

Things that Could Have Been Done and Should be Done for Future Evaluations:

1. Coordinate with implementing partners from the onset in developing and implementing the impact evaluation, in particular to be able to clearly identify program areas.

2. Gather comprehensive information on previous development programming and use this as controls in the analysis or as a basis for stratification in the analysis.

3. Cleary articulate a theory of change at program commencement.

Understanding the effectiveness of interventions in the midst of active conflict is essential to the development of effective policies to address both the pressing needs of the population and the causes of instability. However, as we illustrate in this review, active conflicts and highly unstable environments create challenges that impede impact evaluation, particularly when evaluators are asked to assess difficult-to-measure outcomes like "stability" in a national-level program with multiple implementing partners.

If the intent is to understand the impact of specific programs on stability, future USAID impact evaluations would yield more firm insights if more rigorous evaluation approaches were applied on a smaller set of well-defined projects. However, this approach was understandably not likely to have been feasible in the Afghanistan context, where an enormous amount of program resources were applied to a very diverse set of programs for which stability or support of the government, however crucial, were indirect outcomes. In this situation, the evaluation needs to clearly spell out the theory (or theories) of change leading from the interventions through the direct outcomes to stability, and rigorously assess whether the direct effects are achieved in addition to measuring ultimate impacts on stability. 


\section{Introduction}

The U.S. government appropriated some \$35 billion for development and humanitarian assistance in Afghanistan during 2002-2015, accounting for approximately 32 percent of the more than $\$ 110$ billion in total U.S. appropriations for Afghan reconstruction during that timeframe. ${ }^{2}$ Of the total appropriations for development and humanitarian assistance, the United States Agency for International Development (USAID) accounted for nearly $\$ 22$ billion or just over 60 percent.

In 2010, USAID formed the Afghanistan Stabilization Unit in order to coordinate all USAID activities with the military - both the U.S. military and International Security Assistance Forces (ISAF) - and the Government of the Islamic Republic of Afghanistan, and in particular the Afghan Ministry of Rural Rehabilitation and Development (MRRD) and Independent Directorate of Local Governance (IDLG). During 2010-2011, the efforts of the Stabilization Unit were to enhance stability by supporting the military-led counterinsurgency strategy. However, in 2012 with the beginning of the transition of security responsibility to the Afghan National Defense and Security Forces (ANDSF), the Stabilization Unit began to shift USAID efforts toward "reinforcing the legitimacy of the government and its effectiveness at the subnational and community levels, and improving communities' resilience to malign, antigovernment actors". 3 This trend would continue through 2015.

In order to independently evaluate the effectiveness of these stabilizing efforts, USAID contracted with Management Systems International to implement a "a third-party monitoring and evaluation (M\&E) program that [used] rigorous social science methods to measure and map changes in stability over time". ${ }^{4}$ MSI formed the Measuring Impact of Stabilization Initiative (MISTI) to develop and implement this third-party monitoring. MISTI relied on two Afghan survey firms - the Afghan Center for Socio-Economic Research and Afghan Youth Consulting to collect survey data during 2012-2015, and a blend of academic researchers and survey specialists to evaluate the findings from these data. ${ }^{5}$

The review examines the methodology and tools developed by MISTI both to measure stability trends and to evaluate program impacts. The intent of this review is to identify strengths and limitations of the approach, and make recommendations for improvement. For this review, the research team analyzed MISTI reports, surveyed relevant academic research, and conducted

\footnotetext{
2 Data are from SIGAR (2015). The largest category of U.S. appropriations was for security-related activities, including the development and sustainment of the Afghan National Defense and Security Forces.

${ }^{3}$ USAID (2013a, p. 2).

${ }^{4}$ https://www.usaid.gov/afghanistan/fact-sheets/measuring-impacts-stabilization-initiatives-misti.

5 This work was funded under AID-306-TO-12-00004.
} 
interviews with relevant USAID program officers and Management Systems International personnel and sub-contractors involved with the collection, analysis, and synthesis of data. Interviews were conducted in Kabul, Afghanistan and Washington, D.C.

\section{USAID Stabilization Unit Programs}

The USAID Stabilization Unit executed four different stabilization programs during the 2012-2015 timeframe. These four programs were designed to be phased-in, as illustrated in Figure 1, so that the earliest programs - the Community Development Program and Community Cohesion Initiative (CCI) - would be focused on building community resilience and cohesions and the later programs - Stability in Key Areas (SIKA) and Kandahar Food Zone (KFZ) - would be focused on supporting economic development and Afghan ministerial capacity. The Stabilization Unit also managed the Afghan Civilian Assistance Program II, designed to "provide support to Afghan families and communities that have suffered losses from military operations against the Taliban, or insurgent attacks on ISAF, ANSF and/or the [Afghan government]".

Figure 1.1: USAID Stabilization Unit Programming during 2012-2015

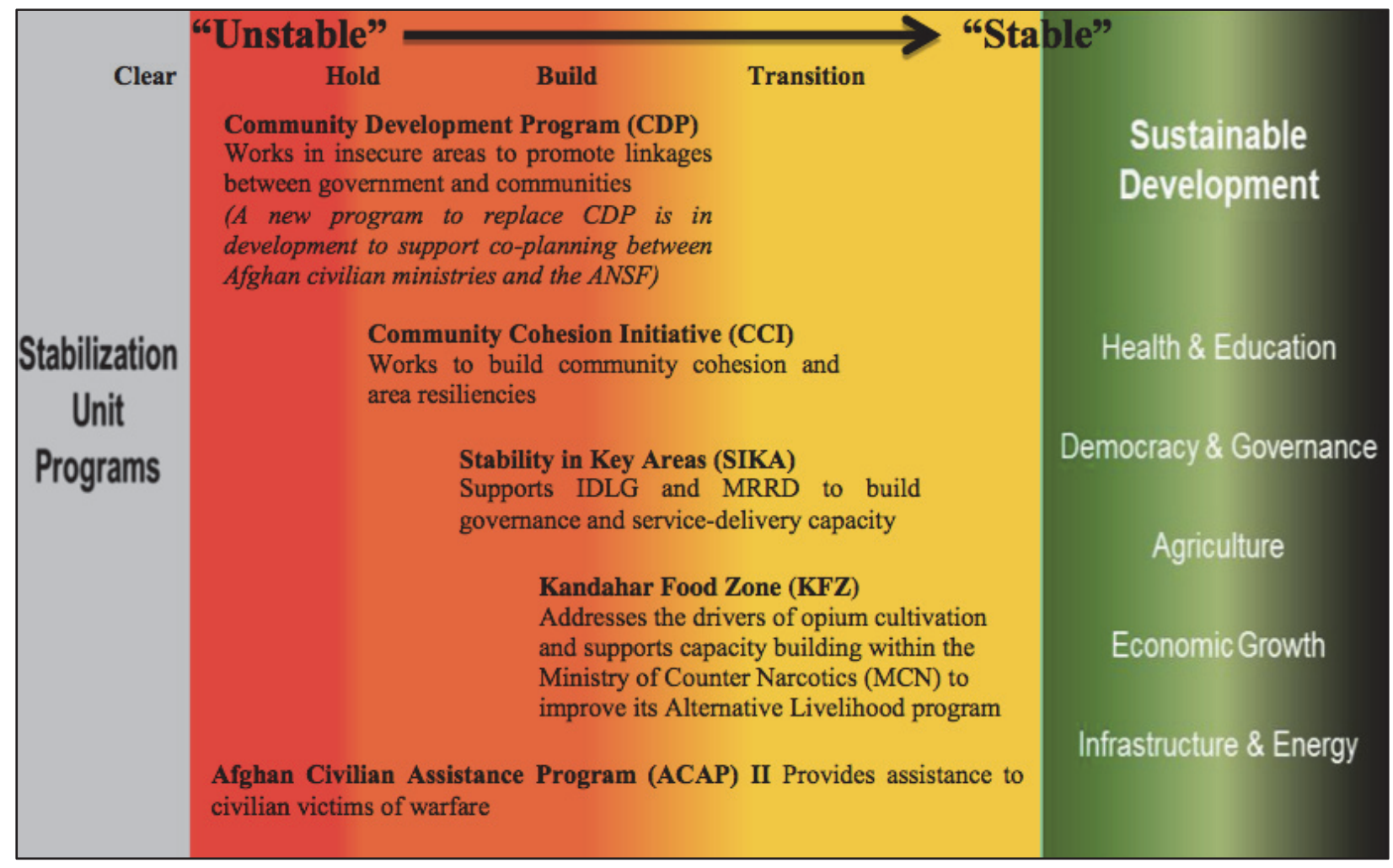

Source: USAID (2014). 
The MISTI impact evaluation, discussed immediately below, focused on three of the four stabilization programs. ${ }^{6}$ The first, the Stabilization in Key Areas (SIKA) program, was intended to promote stability by supporting MRRD and IDLG efforts to implement community-led development and governance initiatives. ${ }^{7}$ This program was implemented through four separate task orders and geographically-aligned offices, with one each focusing on the North, South, East, and West. ${ }^{8}$ Although beyond the scope of the current review, this multitude of international actors working through a single national-level mechanism is reported to have created coordination problems for the MRRD and IDLG personnel working with SIKA. ${ }^{9}$

The second, the CCI, was intended to enhance resilience by strengthening connections across communities and between communities and the Afghan government. ${ }^{10} \mathrm{CCI}$ was administered through the provision of clusters of small grants at the district- or village-level. CCI was implemented by two separate USAID contractors, with Creative Associates International working in the East of Afghanistan and the International Organization for Migration working in the North and West. ${ }^{11}$

The third is the KFZ, which was designed to discourage poppy cultivation, encourage "licit economic growth", and enhance the perceived effectiveness and legitimacy of Afghan government institutions. ${ }^{12}$ The KFZ was charged with identifying and addressing the "drivers of poppy cultivation", and provides grants for "activities that improve community infrastructure, strengthen alternative livelihoods (AL), and support small businesses" in seven districts of Kandahar. ${ }^{13} \mathrm{KFZ}$ also implemented capacity building programs for the Afghan Ministry of Counter Narcotics.

\footnotetext{
${ }^{6}$ For the Community Development Program, MISTI conducted only a program evaluation as the program terminated in late 2013 and there was thus insufficient time to include it within the MISTI impact evaluation.

7 “USAID Stabilization Unit Afghanistan: Performance Management Plan, Fiscal Years 2012-2105” (p. 6).

${ }^{8}$ SIKA-East is a $\$ 177$ million dollar effort managed by AECOM but implemented through (1) International Relief and Development, (2) Development Transformation, (3) GardaWorld, (4) Technologists Inc., and (5) Overseas Strategic Consulting, LTD (AID-306-C-12-00002, p. 46). SIKA-North is a $\$ 46$ million dollar effort managed by DAI but implemented through (1) ACSOR Surveys, (2) Pax Mondial, (3) Sayara, (4) The Liaison Office, (5) Training Resources Group, and (6) URS Corporation (AID-306-C-12-00003, p.44). SIKA-South is a \$60 million dollar effort managed by AECOM but implemented through (1) International Relief and Development (IRD), (2) Technologists Inc., and (3) Overseas Strategic Consulting, LTD (AID-306-C-13-00003, p.50). SIKA-West is a \$63 million dollar effort managed by AECOM but implemented through (1) International City/County Management Association (ICMA), (2) GardaWorld, (3) Technologists Inc., and (4) Overseas Strategic Consulting, LTD (AID306-C-12-00004, p.41).

${ }^{9}$ As this could have important implications for the effectiveness of the programs themselves, a separate qualitative evaluation effort exploring this issue may be warranted. Note that, in addition to this, at least one of the implementing teams faced challenges in the rapid turnover of personnel (USAID 2014a).

10 “USAID Stabilization Unit Afghanistan: Performance Management Plan, Fiscal Years 2012-2105” (p. 6).

${ }^{11} \mathrm{CCI}$ in the East is implemented under AID-DOT-I-08-00034. The task order for CCI in the North and West was not discoverable by these authors.

${ }^{12}$ USAID Cooperative Agreement AID-306-A-13-00008.

${ }^{13}$ USAID (2014b).
} 


\section{Overview of MISTI}

The programming of USAID's Afghanistan Stabilization Unit was designed to achieve "sufficient stability... to enable transition to Afghan-led sustainable development." "14 In order to assess the effectiveness of USAID programming against this objective, MISTI was therefore "designed to measure and map stabilization trends and stabilization program impacts". 15

MISTI assesses the stabilization impact of USAID programming in two ways. The first measures the impact of SIKA, CCI, and KFZ on (1) stability and (2) support among the population for the Afghan government. This impact evaluation compares households' perceptions of stability and reported support for the Afghan government in communities with USAID programming to those without.

The second traces stability trends over time in districts where USAID programming is being implemented. MISTI's approach relies on a district-level stability index, which is compared over time and to districts without USAID programming. This allows MISTI to "inform USAID decision makers and implementing partner managers of changes in stability occurring in the districts where USAID stabilization programming is taking place across Afghanistan, and control districts, and help identify improvements and declines in stabilization in their areas of responsibility". 16

Both the impact evaluation and the analysis of stability trends rely on the same data, a semiannual household survey with approximately 2,500 villages and 35-40,000 households in each wave. ${ }^{17}$ This household survey was collected by two Afghan survey firms, Afghan Center for Socioeconomic and Opinion Research (ACSOR) and Afghan Youth Consulting. ${ }^{18}$ The overall survey consisted of a short community survey completed by the enumerators and a household survey with a demographic module and opinion questions focused on ten different "substantive"

\footnotetext{
${ }^{14}$ USAID (2014b, p. 10).

${ }^{15}$ USAID (2014b, p. 12). The document clarifies that the "inputs and outputs at the project and activity levels are often similar to traditional development projects, stability operations identify and implement activities with the distinctly different objective of diminishing or eliminating [sources of instability], defined as local issues that: 1) decrease support for [the Afghan government]; 2) increase support for antigovernment elements; and, 3) disrupt the normal functioning of society. Tracking developmental activity outcomes such as improved water supply, access to jobs, more productive agriculture, and access to quality education is important to demonstrate that projects are producing desired results. However, these output measures are secondary to progress in areas (i.e., outcomes) such as increased public support for [the Afghan government] and its institutions and increased levels of community cohesion and area resiliency, which are thought to deny insurgents the possibility of drawing support from the local populace." (USAID 2014b, p. 12-13, authors' emphasis - not in original).

16 "MISTI Stabilization Trends and Impact Evaluation Survey Analytical Report, Wave 3" (Preliminary Draft).

17 The first wave was collected in Fall 2012. Data from wave 4 of the survey was being collected and prepared for analysis at the time that this document was originally written.

${ }^{18}$ A total of 1,309 ACSOR interviewers and 41 Afghan Youth Consulting interviewers were involved in the Wave 3 data collection, though the number of interviewers varies across the waves of data collection. Afghan Youth Consulting personnel were used for districts that ACSOR had difficulty accessing. USAID (2014d, p. 10)
} 
areas. ${ }^{19}$ Data from the household survey is the primary input for the MISTI "stability index", though (1) qualitative reporting on local conditions, (2) assessed accessibility of a district, and (3) number of violence incidents are also used in constructing this index. ${ }^{20}$ Therefore when we refer to 'stability' as a measured outcome throughout this report, it should be kept in mind that the measures combine subjective perceptions of households and objective measures.

The household survey also tries to assess the level of support within a community for the Taliban versus Afghan government using an "endorsement experiment". Rather than ask respondents directly whether they support the Taliban or Afghan government - since it is reasonable to believe that respondents will be reluctant to be fully honest in their responses - the endorsement experiment assesses Taliban support indirectly. Households are asked a series of questions about their views toward a set of political issues, for example:

"It has recently been suggested by the [Afghan government/Taliban] that people be allowed to vote in elections to select the members of their district council. Do you oppose or support such a policy, or are you indifferent to this policy? Do you strongly or only somewhat oppose/support?"

For each question, households are randomly sorted into two equal groups. One is told that the Taliban support that policy and the other half are told that the Afghan government supports that policy. The idea is that the researcher can infer support for the Taliban by examining whether communities are more likely to favor policies reportedly supported by the Taliban or, conversely, by the government.

\section{This Report}

The review examines the methodology and tools developed by MISTI both to measure stability trends and to evaluate impacts. The intent of this review is to identify strengths and limitations of the approach, and identify recommendations for improvement. For this review, the research team analyzed MISTI reports, surveyed relevant academic research, and conducted interviews with relevant USAID program officers, MSI survey specialists, and academic researchers supporting the MISTI evaluation.

The following four sections describe the key challenges facing the MISTI evaluation, how these issues may be resolved, and implications for future evaluations in conflict settings. The

\footnotetext{
19 These ten substantive areas are as follows: (1) Security and Crime, (2) Governance, (3) Service Provision and Development, (4) Rule of Law, (5) Corruption, (6) Quality of Life, (7) Economic Activity, (8) Community Cohesion and Resilience, (9) Grievances, and (10) Media (USAID 2014d, p. 266).

${ }^{20}$ Data from the household survey accounts for $75 \%$ of the stability index. Qualitative reporting on local conditions, which accounts for $10 \%$ of the index, is based on a single community-level question that enumerators are asked to complete which describes the perceived level of activity of different types of security forces (e.g., Taliban, ISAF, Afghan, local) in that community. District permissiveness, also accounting for $10 \%$, is based on based on ACSOR's "Accessibility Tracker". Number of violent incidents, accounting for $5 \%$, is based on data from United Nations Department of Safety and Security and the British Embassy (USAID 2014b).
} 
subsequent section, Section 2, discusses the problem faced by not having a clearly articulated theory of change guiding the programming of USAID implementing partners. Section 3 then focuses on issues related to measuring stability, and describes how the "stability index" and "endorsement experiment" are unlikely sufficient for evaluating the impact of programming on stability or government support. Section 4 describes challenges in the empirical setup, focusing on issues related to the quasi-experimental approach and treatment village misclassification.

Section 5 discusses limitations faced in the generalizability of the MISTI findings. We conclude by describing how subsequent waves of MISTI can be improved and discuss general implications for evaluation research in conflict settings. 


\section{Theory of Change}

The intent of the MISTI impact evaluation is to assess the impact of USAID-funded stabilization programs on stability and resilience. Properly assessing these programs requires articulating how this programming may be influencing stability and resilience - which is what is called the "theory of change".

While the program documents outlining MISTI's evaluation provide a clear definition of stability and how USAID programming will impact stability and resiliency, ${ }^{21}$ there was not a theory of change guiding this USAID programming itself. This is true for both specific programs - e.g., at least one of the regional Stabilization in Key Areas (SIKA) programs did not have "a defined theory of change articulated in its contract, approved [Performance Management Plan], or work plan",22 - and for overall USAID lines of effort - e.g., the Community Cohesion Initiative was not guided by a single theory of change, but rather implementers reportedly followed some combination of both counterinsurgency theory and community cohesion. ${ }^{23}$

Given the heterogeneity in the programs being evaluated, as illustrated in Figure 2.1, the lack of an underlying theory of change creates challenges for evaluation. As an example, while infrastructure, vocational training, and community cohesion programs are anticipated to have direct benefits for socioeconomic conditions and political participation, the mechanisms underlying the relationship with stability and resiliency for each are not obvious and not clearly specified. The issue is further complicated by the fact that the type of intervention, and the implementation approach (e.g., who participated in project selection and execution), is likely to be impacted by both the program design and pre-existing degree of stability in that area. ${ }^{24}$

\footnotetext{
${ }^{21}$ The definition of stability in the MISTI Performance Management Plan provides a definition of stability that is clearly linked to USAID programming: "Stability may be defined as the prevailing belief in and support for the decisions and actions of local leaders and government that affect the lives of people in a given community... People in stable areas judge physical security, quality of life, economic opportunities, community relations, and local leaders to be satisfactory. They also generally believe that they receive fair treatment from their local government and legal authorities, and find the daily elements of life to be predictable. Stability is most evident when citizens believe that local leadership and government effectively serves their interests. Stability is strengthened by the presence of a vibrant civil society, ensuring that all groups in society - for example, women and minorities - are able to meaningfully participate in the social and political life of the community.”(USAID 2013a, p. 1).

22 "Stability in Key Areas - West: Mid-term Performance Evaluation”, 26 March 2014.

23 “Community Cohesion Initiatives: Mid-Term Performance Evaluation Report", 15 May 2014.

24 This would create a form of omitted variable bias (Section 5) called "endogeneity" which could lead to unreliable results from the evaluation.
} 
Table 2.1: Types of USAID Programming

\begin{tabular}{|c|c|c|}
\hline \multicolumn{2}{|c|}{ USAID Program } & Example Projects $^{\dagger}$ \\
\hline \multirow{4}{*}{ SIKA } & East & $\begin{array}{l}\text { I School Boundary Wall Constrcution } \\
\text { I Embroidery Vocational Course Training \& Embroidery Machine Supply } \\
\text { I Tertiary Road Gravelling } \\
\text { I Digging new wells and installing hand pumps }\end{array}$ \\
\hline & North & $\begin{array}{l}\text { Increasing Stability among Youth through a University Prep Exam Course (Concur) } \\
\text { I Connecting GIRoA with farmers through celebrating New Year and farmer's day } \\
\text { I Linking Afghan Youth with District Entities through English Courses } \\
\text { I Increasing Community's Trust on the District Government through village road gravelling }\end{array}$ \\
\hline & South & $\begin{array}{l}\text { I Workshop: Access to GIRoA Services } \\
\text { I Irrigation Project } \\
\text { I Road and/or Culverts } \\
\text { I Vocational Training }\end{array}$ \\
\hline & West & $\begin{array}{l}\text { Mobile Phone Repair Vocational Training } \\
\text { I Culvert Construction } \\
\text { I Community Based Health Education Course (CHA) } \\
\text { I Tailoring Vocational Training Program }\end{array}$ \\
\hline \multirow{2}{*}{$\mathrm{CCl}$} & reative & $\begin{array}{l}\text { Tailoring Training: Income Generation Opportunities for Female Youth } \\
\text { Promoting Justice and Stability through Conflict Resolution Training } \\
\text { Extending the reach of peaceful elections messaging through radio } \\
\text { Sahib Jan Rural Sub-Road Repair: GIRoA Connecting Communities }\end{array}$ \\
\hline & IOM & $\begin{array}{l}\text { I Guzara Youth Art Peace Championship: Promoting Peace and Tolerance } \\
\text { I Adraskan Football Tournament: Sports for Tolerance } \\
\text { I Promoting peaceful transition on Highway 1: Equipping the Jahan Khan School } \\
\text { I Promoting Stability Around the Airport: Rehabilitating Retaining Wall, Gawashan }\end{array}$ \\
\hline \multicolumn{2}{|l|}{ KFZ } & $\begin{array}{l}\text { Women's Vegetable Production and Processing Project } \\
\text { Vocational Training in Mechanical Repairs of Machinery } \\
\text { Check Dam Construction Asodah } \\
\text { Irrigation Canal Sangi-Hisar }\end{array}$ \\
\hline
\end{tabular}

An evaluation that treats all programs equally is therefore anticipated to provide unreliable results. Each of these different types of programs is anticipated to impact stability through different pathways and over different timelines. Further, different types of data are likely required for understanding each of the different types of programming. As an important example, understanding the effectiveness of agriculture projects requires detailed data on rainfall during the period of observation, and almost all projects require data on the presence and activity of both host nation and international military forces. ${ }^{25}$

In order to deal with this heterogeneity in program design, the MISTI evaluation team should consider adjusting their evaluation approach in a way that leverages their deep understanding of the geography and intent of each project and broad range of potential outcome measures in their household survey data. As an example, in addition to testing whether a project designed to

${ }^{25}$ E.g., Berman, Felter, and Shapiro (2011). 
improve district government capacity improved stability and resiliency, they should also test whether it did in fact impact district governance performance, since the implied theory of change posits that this is a necessary condition for the program to improve stability and resiliency. Indeed, if a project improved district governance (an importance goal in its own right) but not stability, we would not want to judge these projects as failures. Further it is possible that that stability has improved but is not well captured in available measures of stability (e.g., perhaps the effects are sufficiently long-term as to be outside the data collection period). On the other hand, if such a project is associated with improves stability but not with improved governance, then the evaluators should be very cautious in inferring that there is actually a causal relation, based on the importance of changes in governance in the theory of change.

\section{Implications}

As the above discussion illustrates, a clearly articulated theory of change supports the design of an intervention by providing clear guidance on where and why desired outcomes might be achieved; and it supports the evaluation of the intervention by guiding evaluators in terms of what information to collect - e.g., what intermediate outcomes, final outcomes, and various other factors that the theory says should affect program success. It also, as just illustrated, helps evaluators interpret the findings and assess their validity. Without a clear theory of change, the evaluation may focus on the wrong outcomes for an intervention, and fail to collect relevant data that may help explain why the intervention works or not-in particular, on intermediate outcomes that are necessary steps to achieving the final stability outcome. This is particularly important in conflict settings where conditions are dynamic, making it more difficult for an evaluation to be able to detect program effect and more important for evaluators to understand why the process may not have gone as intended.

It should be noted that we are not recommending eliminating heterogeneity in program design by making programs alike. As long as heterogeneity reflects the fact that programming is needed to meet a diverse range of objectives, not just stability, this would hardly be desirable. However, even if stability is a secondary goal or outcome of many of the programs, an appropriate theoretical framework - theory of change - is needed to link them to stability and develop the appropriate information base for the evaluation of their success toward meeting stability objectives. 


\section{Measurement}

MISTI's ability to effectively measure two key outcomes — stability and Taliban support — is essential to the reliability of both the impact evaluation and effort to track district-level trends. However, both MISTI's stability index and "endorsement experiment" face limitations. We consider these in this section.

The stability index as currently formulated is unlikely to provide a meaningful or useful tool for tracking stability over time. It faces two primary challenges, namely that it combines a mixture of characteristics that are quantitatively and qualitatively distinct, and that the weights used to construct the index were arbitrarily selected. However, these challenges can be overcome. Specifically, we recommend that MISTI reconstruct the stability index using factor analytical methods and validate the stability index using additional external data.

The endorsement experiment provides a potentially powerful tool for measuring support for the Afghan government versus Taliban. However, as this approach relies on subtle word variation across surveys, we recommend additional analyses using both the MISTI survey data and ancillary data (e.g., history of violence, qualitative reporting on local Taliban support from implementing partners) to validate the insights from this approach.

Given the increasing focus of USAID and other donors on enhancing stability, there is a growing need to develop credible tools for measuring stability and relative support for the government and for non-state actors. The experiences of MISTI - both their successes and challenges - offer valuable lessons for future impact evaluations in fragile states.

\section{Measuring Stability}

The primary tool that MISTI uses to measure stability is a "stability index" which is a composite of information from MISTI's household survey data, district-specific reporting on local conditions collected by ACSOR, and reporting on local security incidents. Additionally, MISTI separately reports overall trends in ten different dimensions of stability based on the household survey. ${ }^{26}$ Though our discussion in this section focuses on the stability index, these concerns are also applicable to this "trend analysis" as the data underlying both approaches for tracking stability are identical.

\footnotetext{
26 These categories are: (1) security and crime, (2) governance, (3) service provision, (4) rule of law, (5) corruption, (6) quality of life, (7) economic activity, (8) community cohesion, (9) grievances, and (10) media.
} 
Table 3.1: Composition of MISTI Stability Index

\begin{tabular}{|c|c|c|c|c|c|}
\hline \multicolumn{3}{|c|}{ Data Source } & Household Survey Question/Variable ${ }^{\dagger}$ & \multirow{2}{*}{$\begin{array}{l}\text { Question- } \\
\text { Specific } \\
\text { Weight }^{\ddagger} \\
3.8 \%\end{array}$} & \multirow{2}{*}{$\begin{array}{l}\text { Total } \\
\text { Weight in } \\
\text { Stability } \\
\text { Index } \\
4 \%\end{array}$} \\
\hline \multirow{8}{*}{$\begin{array}{l}\text { Household } \\
\text { Survey }\end{array}$} & 1 & Security & Is the area more or less secure than a year ago? & & \\
\hline & 2 & Right Direction & Are things in this district going in the right or wrong direction? & $3.8 \%$ & $4 \%$ \\
\hline & 3 & $\begin{array}{l}\text { Confidence in } \\
\text { Government }\end{array}$ & $\begin{array}{l}\text { Is Afghan government well regarded in this area? } \\
\text { How much confidence do you have in your district government? } \\
\text { How responsive is your district government? } \\
\text { Has the district government's efficacy improved or worsened? } \\
\text { How much confidence do you have in your District Development Assembly? } \\
\text { How responsive is your District Development Assembly? } \\
\text { Has the District Development Assembly's efficacy improved or worsened? } \\
\text { How much confidence do you have in your Community Development Council? } \\
\text { How responsive is your Community Development Council? } \\
\text { Has the Community Development Council's efficacy improved or worsened? } \\
\text { District government officials from district? } \\
\text { District government understands problems? } \\
\text { District government cares about people? } \\
\text { District government abuses authority for money? } \\
\text { District government officials visit area? } \\
\text { District government officials are honest? } \\
\text { District government delivers basic services? }\end{array}$ & $\begin{array}{l}2.3 \% \\
6.8 \% \\
2.3 \% \\
1.1 \% \\
0.6 \% \\
0.6 \% \\
0.6 \% \\
0.6 \% \\
0.6 \% \\
0.6 \% \\
1.0 \% \\
1.0 \% \\
1.0 \% \\
1.0 \% \\
1.0 \% \\
1.0 \% \\
1.0 \% \\
\end{array}$ & $23 \%$ \\
\hline & 4 & Quality of Life & $\begin{array}{l}\text { How satisfied are you with life? } \\
\text { How is your financial situation? } \\
\text { Has your ability to meet basic needs increased this past year? } \\
\text { How worried are you about basic needs during next year? } \\
\text { Is the area certain enough to make plans? } \\
\text { Is you area more or less secure than last year? }\end{array}$ & $\begin{array}{l}1.7 \% \\
1.7 \% \\
1.1 \% \\
1.1 \% \\
2.3 \% \\
3.4 \%\end{array}$ & $11 \%$ \\
\hline & 5 & Resiliency & $\begin{array}{l}\text { How often can people solve problems from outside the village? } \\
\text { How often can people solve problems from inside the village? } \\
\text { Do villages work together to solve problems in the area? } \\
\text { Are interests of ordinary people included in local leader decisions? } \\
\text { Are local leaders effective in securing funding for development projects? } \\
\text { Do you belong to any groups that discuss issues or take action? } \\
\text { How much confidence do you have in your district governor? } \\
\text { How much confidence do you have in your district government? } \\
\text { How much confidence do you have in your local leaders? } \\
\text { How much confidence do you have in your provincial governor? } \\
\text { How responsive is the district governor to the needs of local people? } \\
\text { How responsive is the district government to the needs of local people? } \\
\text { How responsive is the local leaders to the needs of local people? } \\
\text { How responsive is the provincial governor to the needs of local people? }\end{array}$ & $\begin{array}{l}1.1 \% \\
0.8 \% \\
2.3 \% \\
0.8 \% \\
1.1 \% \\
0.6 \% \\
0.6 \% \\
0.6 \% \\
0.6 \% \\
0.6 \% \\
0.6 \% \\
0.6 \% \\
0.6 \% \\
0.6 \%\end{array}$ & $11 \%$ \\
\hline & 6 & $\begin{array}{c}\text { Government } \\
\text { Services }\end{array}$ & Have government services in this area improved? & $11.3 \%$ & $11 \%$ \\
\hline & 7 & Corruption & Is corruption a problem in your areas? & $3.8 \%$ & $4 \%$ \\
\hline & 8 & $\begin{array}{c}\text { Presence of } \\
\text { Armed Groups }\end{array}$ & How would you rate the presence of armed opposition groups in your area? & $7.5 \%$ & $8 \%$ \\
\hline \multirow{3}{*}{\multicolumn{3}{|c|}{$\begin{array}{l}\text { MISTI Survey } \\
\text { ACSOR Accessibity Index } \\
\text { Security Incidents }\end{array}$}} & \multicolumn{2}{|l|}{ What types of security forces are based in this village or nearby? } & $10 \%$ \\
\hline & & & \multicolumn{2}{|l|}{ How safe is the district? } & $10 \%$ \\
\hline & & & \multicolumn{2}{|l|}{ How many security incidents in the district from MAY-AUG 2013? } & $5 \%$ \\
\hline \multicolumn{6}{|c|}{$\begin{array}{l}\text { †: Wording of questions in this table are paraphrased versions of the questions specified in Appendix D of USAID (2014c). The specific coding of } \\
\text { responses is also presented in Appendix D. }\end{array}$} \\
\hline \multicolumn{6}{|c|}{$\begin{array}{l}\text { ¥: Estimates of the contribution of individual household survey questions are the authors' estimates based on the weighting scheme delineated in } \\
\text { Appendix D of USAID }(2014 \mathrm{c}) \text {. This appendix provides "Overall Weights" which sum to } 5 \text { across all eight major categories and "Var weights" which } \\
\text { sum to } 5 \text { within categories. The authors combine these numbers, assuming that the total value is } 75 \% \text {, which is the total value assigned to the } \\
\text { household survey questions. This approach matches the results produced in Appendix B of that report. }\end{array}$} \\
\hline
\end{tabular}

The stability index is a composite of 45 different factors. A total of 42 different questions from the MISTI household survey, organized into eight different categories, account for 75 
percent of the total value of the stability index; a measure of local control based on the MISTI household survey data collectors themselves accounts for 10 percent; ACSOR reporting on district "accessibility" accounts for an additional ten percent; and security incidents account for five percent. The 45 different factors and their individual weights are summarized in Table 2.1; the 42 questions from the household survey are organized into their eight different categories.

The MISTI stability index, while desirable from a policy perspective as it facilitates ease of comparison across time and space, is unlikely to provide a meaningful or useful tool for tracking stability over time because of three major challenges. The first challenge is that this single index combines factors that are qualitatively different, that is, represent different things. Unlike other frequently used indices, such as asset indices that include ownership of a range of different durable goods, the stability index includes factors as diverse as "corruption" and "presence of armed groups". One way of illustrating the magnitude of this challenge is by calculating the pairwise correlations of all the household survey questions in the index. If all the variables are measuring aspects of the same thing - i.e., stability - then they should all be positively correlated. However, we find that more than $40 \%$ of the pairwise correlations have values that are negative or statistically indistinguishable from zero and fewer than $40 \%$ are greater than 0.1 (results not reported).

The second challenge is that the weights used for constructing the index seem to have been selected based on a priori judgments of the team. ${ }^{27}$ These may be well informed, but this process ignores widely accepted approaches for combining multiple, potentially different factors, into a single index which essentially allow the data to determine the appropriate weights as well as assess the similarity or dissimilarity of different variables. ${ }^{28}$ For example, exploratory factor analysis would provide the researcher weights, indicate which variables can be discarded as being redundant or irrelevant, and identify whether there are multiple "underlying factors" that are driving these observable variables; the last is of particular relevance here given that stability is apparently a multidimensional concept.

The current stability index as it stands is therefore a problematic measure, whether it is used for tracking changes in stability over time or for measuring the impact of USAID development programming. In terms of trying to track stability, either for the impact evaluation or the districtlevel trend analysis, the researchers should consider a two-pronged approach. First, starting with the 42 identified household survey questions and the three additional measures, the researchers should use factor analytical methods in order to (1) explore the relationship between these

\footnotetext{
${ }^{27}$ The deleterious impact that arbitrary weights can have on inference in this type of setting is illustrated by Pande and Udry (2005).

${ }^{28}$ Bohrenstedt (2010).
} 
variables, with a particular focus on trying to understand how many different relationships that these variables are measuring, and (2) develop defensible data-driven weights. ${ }^{29}$

Second, the researchers should validate their stability index using other available data sources. This could be done internally - by comparing how the stability index in the first wave of data correlated with subsequent violence, governance challenges, and challenges in implementing development programs in later waves. Additionally, the research team should coordinate with ISAF and other representatives of the U.S. Department of Defense to assess the relationship between their own measures of stability and other, independent, measures of stability based on other data.

Third, although the researchers do discuss individual components separately for the trend analysis, the impact evaluation only assesses changes in the index, that is, across all 45 variables simultaneously. The MISTI impact evaluation should first explore the potential impact that the programming had on its intended outcomes. In some cases these outcomes will be a component of the stability index, and in other cases they will not.

\section{Measuring Support for Taliban}

In addition to assessing changes in stability, a secondary goal of MISTI was to use the household survey to assess whether USAID programming impacted the "population's support for the [Afghan government] and the Taliban". ${ }^{30}$ Recognizing that respondents in the survey would be unlikely to report truthfully about their views toward the Taliban in a survey - at least one Afghan survey firm reported that asking direct questions about the activity of non-state actors was often met with trepidation and also affected responses throughout the rest of the survey ${ }^{31}-$ the MISTI used an "endorsement experiment" in order to try to capture support for the Taliban as compared to the Afghan government.

Rather than ask respondents directly, the endorsement experiment tries to assess Taliban support indirectly by examining whether interviewees are more likely to support a given political viewpoint if they are told that the Taliban supports that viewpoint. With a village, $50 \%$ of surveyed households (randomly selected) are told that the Taliban support a series of policies and the remaining 50\% are told that the Afghan government supports the same set of policies - the set of questions for each of these two groups are provided verbatim in Table 3.2. To be clear,

\footnotetext{
${ }^{29}$ E.g., Bohrenstedt (2010). We note that additional analysis conducted by MISTI, in response to the original draft of this report, demonstrated that government confidence and community resiliency should be divided into three separate sub-indices for analysis, and that the overall stability index may need to be divided into as many as nine different indices (MSI 2014).

${ }^{30}$ USAID (2014b, p. 13).

${ }^{31}$ Author correspondence with Eureka personnel. A secondary concern is that there is often regional variation in terms of the terminology that people use for describing these different organizations. Most Afghan survey firms work with locally based researchers that are cognizant of these issues, but the use of different terminology across regions can introduce unwanted heterogeneity in terms of responses.
} 
half of the households in a village are asked only the questions from the first column of Table 3.2, and the other half are only asked questions from the second column. And if more households with the series of "Taliban support" prompts are likely to support specified policies then the village is determined to be "pro-Taliban", and vice versa.

Table 3.2: Questions for Endorsement Experiment

\begin{tabular}{|c|c|}
\hline "Afghan Government” Group & “Taliban” Group \\
\hline $\begin{array}{l}\text { It has recently been suggested by the Afghan } \\
\text { government that people be allowed to vote in elections to } \\
\text { select the members of their district council. Do you } \\
\text { oppose or support such a policy, or are you indifferent to } \\
\text { this policy? Do you strongly or only somewhat } \\
\text { oppose/support? }\end{array}$ & $\begin{array}{l}\text { It has recently been suggested by the Taliban that people be } \\
\text { allowed to vote in elections to select the members of their } \\
\text { district council. Do you oppose or support such a policy, or are } \\
\text { you indifferent to this policy? Do you strongly or only } \\
\text { somewhat oppose/support? }\end{array}$ \\
\hline $\begin{array}{l}\text { It has recently been suggested by the Afghan government that } \\
\text { expensive new prisons be constructed in every district to help } \\
\text { alleviate overcrowding in existing prisons. Do you oppose or } \\
\text { support such a policy, or are you indifferent to this policy? Do } \\
\text { you strongly or only somewhat oppose/support? }\end{array}$ & $\begin{array}{l}\text { It has recently been suggested by the Taliban that expensive } \\
\text { new prisons be constructed in every district to help alleviate } \\
\text { overcrowding in existing prisons. Do you oppose or support } \\
\text { such a policy, or are you indifferent to this policy? Do you } \\
\text { strongly or only somewhat oppose/support? }\end{array}$ \\
\hline $\begin{array}{l}\text { It has recently been suggested by the Afghan government that } \\
\text { the weak Independent Election Commission (IEC) be } \\
\text { strengthened to prevent election fraud. Do you oppose or } \\
\text { support such a policy, or are you indifferent to this policy? Do } \\
\text { you strongly or only somewhat oppose/support? }\end{array}$ & $\begin{array}{l}\text { It has recently been suggested by the Taliban that the weak } \\
\text { Independent Election Commission (IEC) be strengthened to } \\
\text { prevent election fraud. Do you oppose or support such a } \\
\text { policy, or are you indifferent to this policy? Do you strongly or } \\
\text { only somewhat oppose/support? }\end{array}$ \\
\hline $\begin{array}{l}\text { It has recently been suggested by the Afghan government that } \\
\text { the weak Office of Oversight for Anti-Corruption be } \\
\text { strengthened by allowing it to collect information about } \\
\text { government officials suspected of wrong-doing. Do you } \\
\text { oppose or support such a policy, or are you indifferent to this } \\
\text { policy? Do you strongly or only somewhat oppose/support? }\end{array}$ & $\begin{array}{l}\text { It has recently been suggested by the Taliban that the weak } \\
\text { Office of Oversight for Anti-Corruption be strengthened by } \\
\text { allowing it to collect information about government officials } \\
\text { suspected of wrong-doing. Do you oppose or support such a } \\
\text { policy, or are you indifferent to this policy? Do you strongly or } \\
\text { only somewhat oppose/support? }\end{array}$ \\
\hline
\end{tabular}

This survey method, which relies on subtle word variation across surveys (e.g., a single word changed in the middle of a sentence), assumes that an individual's support for the statements will be influenced by the reference to either the "Afghan government" or the "Taliban"; this is referred to in the academic literature as the "latent level of support". ${ }^{32}$ In order to illustrate the rough magnitude size of this latent level of support, in Table 3.3 we report the correlations of the group of individuals asked the "Afghan government" questions and the group asked the Taliban questions. All these correlations are positive, suggesting that these group identities are indeed salient, though these correlations are also anticipated to capture individuals' latent level of support for good policymaking. ${ }^{33}$

The level of support in a given village for the Taliban as compared to the Afghan government is calculated by comparing the estimated latent level of support for each group. Specifically, the individuals assigned to the "Afghan government" sample are used to calculate the latent level of

32 Blair, Imai, and Lyall (p. 11).

33 Given the similarity in the correlations across the two groups of individuals, it is possible that this latent level of support for good policymaking might be quite large. 
support for the Afghan government, and the comparable analysis is then done for the "Taliban" sample. Comparing these two estimates gives an overall estimate of a village's level of support for the Taliban.

Table 3.3: Correlation among Endorsement Experiment Questions

\begin{tabular}{|c|c|c|c|c|c|c|c|c|c|c|c|}
\hline \multicolumn{6}{|c|}{ Afghan Government } & \multicolumn{6}{|c|}{ Taliban } \\
\hline & & Q1 & Q2 & Q3 & Q4 & & & Q5 & Q6 & Q7 & Q8 \\
\hline Q1 & $\begin{array}{l}\text { Afghan government believes } \\
\text { people should elect district } \\
\text { council }\end{array}$ & 1.00 & & & & Q5 & $\begin{array}{l}\text { Taliban believes people } \\
\text { should elect district council }\end{array}$ & 1.000 & & & \\
\hline Q2 & $\begin{array}{l}\text { Afghan government believes } \\
\text { expensive new prisons should } \\
\text { be built }\end{array}$ & $0.12^{*}$ & 1.00 & & & Q6 & $\begin{array}{l}\text { Taliban believes expensive } \\
\text { new prisons should be built }\end{array}$ & $0.16^{*}$ & 1.000 & & \\
\hline Q3 & $\begin{array}{l}\text { Afghan government believes } \\
\text { action should be taken } \\
\text { against electoral fraud }\end{array}$ & $0.10^{*}$ & $0.22 *$ & 1.00 & & Q7 & $\begin{array}{l}\text { Taliban believes action } \\
\text { should be taken against } \\
\text { electoral fraud }\end{array}$ & $0.13^{*}$ & $0.17^{*}$ & 1.000 & \\
\hline Q4 & $\begin{array}{l}\text { Afghan government believes } \\
\text { more action should be taken } \\
\text { against corruption }\end{array}$ & $0.10^{*}$ & $0.15^{*}$ & $0.23^{*}$ & 1.00 & Q8 & $\begin{array}{l}\text { Taliban believes more action } \\
\text { should be taken against } \\
\text { corruption }\end{array}$ & $0.10^{*}$ & $0.08^{*}$ & $0.21^{*}$ & 1.000 \\
\hline
\end{tabular}

Note: Authors estimates of MISTI survey data. Results include data from Waves 1 and 3 only, and only communities that were included in both Waves 1 and 3. "*” indicates significant at the 1-percent level.

This endorsement experiment provides a potentially powerful tool for measuring the impact of programs on support for the Afghan government. However, we recommend that the MISTI team provide additional analyses to verify that their endorsement experiment is indeed measuring support for the Taliban versus Afghan government. ${ }^{34}$

The first approach would be to use other data from within the household survey, based on the underlying theory of change specified in the MISTI evaluation, to validate the results from experiment. Simple exploratory analyses - e.g., the correlation of Taliban support with poverty, access to government services, confidence in security services, etc. - would be a simple but useful approach. A second approach would be to use available ancillary data (e.g., history of local stability, Taliban violence) in a similar way to validate the estimates of support. A third approach going forward would be to build into the fieldwork interviews with local leaders or key informants on the degree of support for the Taliban and the government in the sampled villages, supplemented by the perceptions of the survey teams themselves. This could provide an important validation of these results.

\footnotetext{
34 In addition to the possible concern that latent support for good policymaking is swamping the latent support for the groups, discussed in the previous footnote, there are two other possible concerns. The first is that there seems to be increasing polarization over time, which may in part explain the reported results between USAID programming and increased Taliban support. In the results from Wave 3, more individuals report supporting and rejecting "Afghan government"-supported policies, with the increase in both groups coming from a decrease in individuals reporting being indifferent; the identical result is seen for the "Taliban"-supported policies. A second concern is that the endorsement experiment does not necessarily address the challenge it was designed to ameliorate - i.e., that interviewees respond inaccurately due to their own trepidation and concern when hearing interviewers ask about the Taliban or Afghan government. The endorsement experiment is assumed to negate this concern, by asking about these groups indirectly, but respondents may be sensitized to references to either of the groups.
} 


\section{Implications}

Given the increasing focus of development programming on improving either stability or support for a particular group (e.g., Afghan government, ISAF), developing reliable approaches to measure stability and support is imperative. Thus, understanding the successes and challenges of MISTI's two major innovations in terms of measurement - namely the stability index and the endorsement experiment - are important for USAID and other development programming in fragile states like Afghanistan.

Our review of MISTI suggests that the stability index and endorsement experiment, given the potential susceptibility of their validity to issues faced in data collection, should be augmented with other data to validate their findings. A single, comprehensive stability index is an attractive feature of an impact evaluation for policymakers, but may be impractical for assessing heterogeneous programming. We recommend that the stability index used by MISTI be disaggregated using factor analytical methods. The disaggregated components should then be validated using ancillary data (e.g., historical violence, etc.), and analysis should be restricted to the components that best measure what MISTI is trying to measure.

Similarly, assessing support for political parties or groups using large-scale national surveys remains an important but difficult to achieve objective. Endorsement experiments are attractive in that they may offer a solution to the problem of respondents' reluctance to state their opinion on these very sensitive topics. However, augmenting the endorsement experiments with other survey-based approaches designed to explore sympathy for non-state actors (e.g., Cragin 2014) or qualitative data collected from implementing partners or local government authorities could help. 


\section{Estimation}

MISTI's impact evaluation studies the impact of SIKA, CCI, and KFZ by comparing communities with USAID programming to communities without it. In this section we explore challenges that emerge from the way in which "treatment" communities (those that receive a USAID project) and "control" or "comparison" communities (those that do not) were selected for inclusion in the MISTI data collection.

As randomization of USAID programming was not feasible, MISTI's empirical estimation approach relies on quasi-experimental methods. Specifically, MISTI uses a statistical "matching" tool in order to find control communities in the MISTI household survey that are similar to treatment communities. Though the MISTI evaluation reports highlight concerns with the efficacy of their matching approach, we provide evidence that these concerns are likely overstated. However, future MISTI evaluations should include other types of matching estimators to validate their results in addition to their "matching on covariates" approach; we specifically recommend that they consider inclusion of the "matching on the propensity score" as an additional specification.

A very basic problem confronting the MISTI impact evaluation team was in the difficulty in accurately identifying which villages in USAID districts received projects and which did not. This challenge was reportedly a consequence of the fact that the implementing partners were unprepared (and not originally contractually obligated) to support an impact evaluation. Well aware of this challenge, the MISTI team implemented a variety of approaches for assessing whether a village has a USAID project or not. Even with these fixes, "misclassification error" can remain and may make program effects harder to detect; this can occur even if only five percent of the villages are misclassified. ${ }^{35}$ Thus, this is a serious concern and MISTI results should be appropriately caveated. This issue is taken up in detail below.

To prevent this problem in future evaluation efforts, it is necessary to involve the implementing partners in the evaluation process by (1) including language in their contracts requiring them to support the evaluation and (2) ensuring close coordination between the evaluator and implementing partners before and during an evaluation. This will ensure that the necessary information is maintained on where the programs are being carried out (and has many benefits beyond meeting this most basic need). As some friction between these different groups is anticipated - e.g., conflict-related delays in project execution or shifts in program areas can impact the efficacy of the evaluation - the international organization sponsoring the research

\footnotetext{
${ }^{35}$ It has been shown in general terms that even a small amount of misclassification (e.g., under 5\%) could make program effects impossible to detect (Kreider 2010).
} 
should ensure that the implementing partners and evaluator meet and discuss challenges and remediation on an ongoing basis.

\section{Quasi-Experimental Approach}

The "gold standard" in impact evaluation is randomized program assignment, or "randomization", using baseline and follow-up surveys. In the MISTI context, this approach would require that the implementing partners (1) identify a sample of villages that qualify for the program and (2) randomly select some villages to receive programs and others to not get the programming, i.e., to act as controls. Alternatively and usually more feasible politically, the latter group would also receive the programs, but only after an interval, during which they can serve as controls.

Randomization was not feasible for the USAID programming being evaluated, and therefore MISTI instead employed a "quasi-experimental" approach. ${ }^{36}$ The intuition of quasi-experimental methods is relatively straightforward. A key characteristic of randomization is that the only difference, statistically speaking, between treatment and control villages is that some received the intervention and others did not; treatment and control villages should therefore be identical on average (that is, allowing for normal variation across villages). Quasi-experimental methods choose control or comparison groups in such a way as to approach this equivalence.

The MISTI evaluation combines two standard quasi-experimental approaches: (1) "matching" and (2) "difference-in-difference". The matching approach uses data from the household survey to identify villages without USAID programming that are similar to villages with USAID programming. MISTI relies on a matching approach known as "matching on covariates", which tries to find control villages for each treatment villages that are identical (or nearly identical) for a set of specified observable characteristics. ${ }^{37}$ Eight observable characteristics are used for this matching - population, elevation, dominant ethnicity, distance to district center, amount of violence in 90 days prior to aid distribution, amount of violent in 90 days after aid distribution, Wave 1 stabilization index, and density of nearby agricultural land. ${ }^{38}$

The difference-in-difference approach further helps adjust for possible non-randomness in project allocation. Specifically, in the MISTI context, it is likely that pre-existing (i.e., before

\footnotetext{
${ }^{36}$ Even if this randomization had been attempted, it is anticipated that there may have been significant challenges including non-compliance, other development donors targeting "control" villages, etc.

${ }^{37}$ MISTI relies on two different types of "matching on covariates" approaches. The first uses an approach called coarsened exact matching (CEM) in which the observable data are "coarsened" (e.g., village size is coarsened from number of households to a discrete indicator for the villages have greater than or less than 1,000 individuals) to make it easier to find matches (e.g., Blackwell et al. 2009 - a user-friendly overview of the approach is provided at http://www.stata.com/meeting/boston10/boston10_blackwell.pdf). The second, nearest-neighbor matching uses a Euclidean-distance like intuition in terms of finding the control villages that are the "closest" across the observable characteristics (e.g., Abadie et al. 2004).

${ }^{38}$ USAID 2014 c, p. 39.
} 
USAID intervention) levels of stability and government support influenced village selection. Thus, a comparison of these outcomes after the stability programs were implemented may merely reflect differences that existed before the programs. Rather than compare levels of the outcomes across program and non-program villages, the difference-in-difference approach compares the changes in outcomes in these two groups. Thus, data is collected from villages both before the program begins ("baseline") and following implementation ("follow-up"). By comparing changes rather than levels, the approach controls for the initial or baseline differences in outcomes. It assumes that difference in changes in the two groups are due only to the program, which is another way of saying that any possible trends or shocks (e.g., a good or bad harvest) affecting outcomes are the same for both groups.

MISTI's quasi-experimental approach faces an important limitation, in that their "matching on covariates" approach may not have been able, at least in some cases, to find sufficiently similar control villages. This concern was highlighted in the MISTI Wave 3 report, which reports that the "villages that have received assistance are different from 'average' villages in our survey, indicating that appropriate 'matches' for intervention villages may not be present in our survey sample" (footnote to Table 2, p.162) and that "in some cases a corresponding match [for treatment villages] could not be found due to differences in socioeconomic or other characteristics" (footnote to Table 4, p. 168). ${ }^{39}$ This suggests that MISTI's quasi-experimental matching approach may have been unable to come up with an appropriate comparison group, at least for certain classes of USAID programming, so the approach is unlikely to produce reliable estimates of the impact of USAID programming. The additional use of difference-in-differences, which focuses on comparing changes in treatment and control villages so does not require strict comparability at baseline, can help ameliorate this to some degree. However, analysis with treatment and control villages that are observably similar is more likely to deliver reliable results.

That that said, our own exploration of this issue, driven by the concerns expressed by MISTI, in fact suggests that the treatment and control villages are sufficiently similar for use in the impact evaluation. We explore this problem - that villages selected for USAID programming and the controls are dissimilar - in Figure 4.1. Rather than using the "matching on covariates" approach, as used by MISTI, we use an alternative common matching approach known as "matching on the propensity score". ${ }^{40}$ Figure 4.1 reports the estimated propensity score for treatment and control villages using available data on population, elevation, Pashtun-speaking village, Dari-speaking village, distance to district center, and historical number of National

\footnotetext{
${ }^{39}$ USAID (2014d). The referenced Table 2 provides a comparison of means across the treatment and control villages and Table 4 provides results using one of the two "matching on covariates" techniques, coarsened exact matching (CEM), as discussed below.

${ }^{40}$ We use the inverse probability weighting (IPW) approach of Wooldridge (2010) as it is easy to implement, requiring the researcher to only (1) estimate a propensity score model in a first-stage and then (2) use the predicted values from this propensity score in a second-stage.
} 
Solidarity Program (NSP) projects. ${ }^{41}$ Importantly, these distributions are qualitatively similar (as can be seen below) and a standard quantitative test for "balancing", which assesses whether there are sufficient control villages to construct a set of control villages that mimic randomization, ${ }^{42}$ suggests that these distributions are sufficiently similar.

Figure 4.1: Comparing Treated and Control Villages

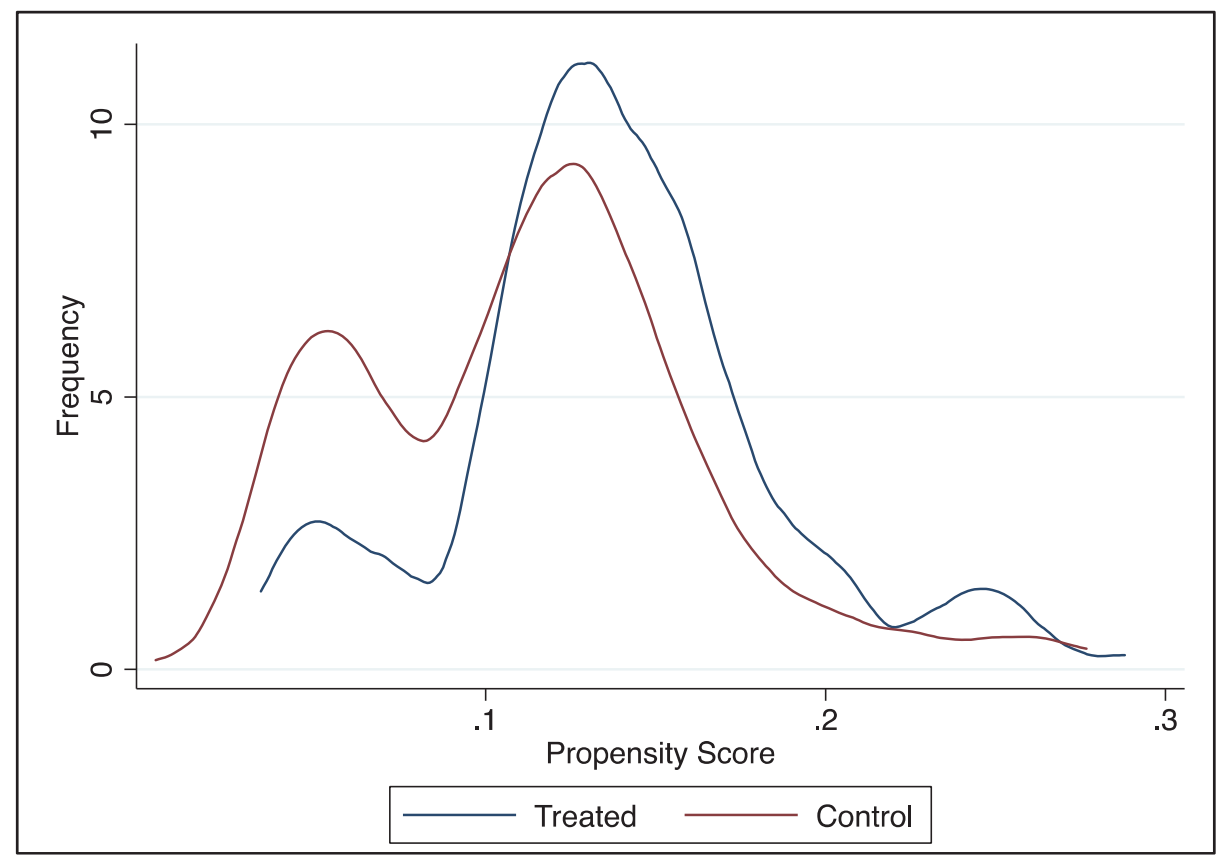

Note: rropensity scores are calculated using the tollowing IVIIS I I-provided variabıes: population, elevation, Pashtun-speaking village, Dari-speaking village, distance to district center, and historical number of NSP projects.

Given the MISTI-identified limitations of their current "matching on covariates" approach, which requires villages to be exactly the same on a small set of characteristics, we therefore recommend that the evaluation team augment their analysis to include other types of matching. Though the "exact match" feature of their approach is attractive, ${ }^{43}$ other methods are also intuitive and may allow more flexibility in this complex environment (as exact matches are not required). The "matching on the propensity score" is one approach that we would recommend, ${ }^{44}$ though there are at least three additional classes of empirical matching estimators that could also

\footnotetext{
41 This represents only a subset of the variables used for matching in the current MISTI impact evaluation. 42 E.g., Becker and Ichino, 2002.

43 Note, further, that these matching on covariates approaches do not have well-behaved statistical properties (e.g., Abadie and Imbens 2006) and in many cases, as is the case for MISTI, finding exact matches can be difficult.

${ }^{44}$ As misspecification of the propensity score model can lead to biased estimates, more recent propensity score methods have been developed that are either doubly robust - i.e., unbiased if either the propensity score model or regression model is correctly specified - (e.g., Inverse Probability Tilting ["IPT"] of Graham, Pinto, and Egel 2012) or robust to mild misspecification of the propensity score (e.g., Covariate Balancing Propensity Score ["CBPS"] of Imai and Ratkovic 2014). Note also that the IPT approach also has the "exact matching" property.
} 
be used here. ${ }^{45}$ Reporting results using different approaches would provide a valuable tool for validating the robustness of MISTI's findings. ${ }^{46}$

Second, the current report does not report any analysis (like that we have just presented) that would allow the reader to assess whether the matching approaches have been "successful" in identifying an appropriate set of control villages. Specifically, Table 2 in USAID (2014d), which currently reports average characteristics for all potential treatment and control villages, should be augmented with a third column that reports control villages selected by the matching on covariates methods. The comparison of the first and third groups would provide a test for the effectiveness of the matching.

Third, the researchers should discuss the variables used for these matching methods with the implementing partners. The goal of this effort would be identify whether there are other factors that did affect the likelihood of a village receiving a project programming which are not included in the currently available data but may have been collected by the implementing partner during their own research-or may be collected in the future.

\section{Identifying USAID Program Villages}

As noted, the MISTI impact evaluation team faced significant problems in identifying the exact villages in which USAID programming was implemented and which it was not. This challenge resulted from two logistical issues. The first was that the implementing partners had not agreed, either amongst themselves or with the MISTI impact evaluation team, on a common village sampling frame for Afghanistan, from which villages would be selected. Second, once the selections of villages were made using the sampling frames at hand, detailed information on the specific villages getting the programs was not systematically recorded by the implementing partners.

The program village location data provided to MISTI by the implementing partners had four types of challenge. First, the specific geospatial data provided for a village often did not match with other data provided for that same village - e.g., the locational information for a project implied it was in district $\mathrm{X}$ while the data provided by the implementing partner indicated that it was in district Y. Second, locational data provided for projects was often incongruous with the type of project being implemented (e.g., a culvert project cannot be implemented in a desert),

\footnotetext{
${ }^{45}$ See e.g., Imbens (2004). As a further example, Bayesian methods (e.g., TWANG of Ridgeway et al. 2012) are popular among statisticians and easily implementable in many widely used statistical packages (http://cran.rproject.org/web/packages/twang/vignettes/twang.pdf). Regardless of the specific empirical approach used, the set-up must meet the same assumption - i.e., the characteristics used to match communities should fully account for differences between the treated and control communities, so that the observed differences in that outcome can be attributed to the program being evaluated. This property is known as "unconfoundedness", or adequate "selection on observables".

${ }^{46}$ A response from Jason Lyall on an earlier version of this report indicated that some such comparisons were in fact done, and that results were similar. We suggest then that these findings be noted in the reports.
} 
hence clearly inaccurate. Third, certain classes of USAID programs by their nature affect more than a single village (e.g., roads), but only one village location was provided. Fourth, the locational information provided to MISTI did not always reference a populated area.

Difficulties identifying which villages in the MISTI household survey received USAID programming will make it hard for the MISTI evaluation to measure program effects. The issue is one of misclassification of treatment and control status - either (1) program villages are misclassified as control villages or (2) control villages are misclassified as treatment villages, or both. ${ }^{47}$ Misclassification is a form of measurement error in a variable. If this error is random, it will, all things equal, lead to estimates that are biased toward zero - i.e., toward finding no effect. ${ }^{48}$ Importantly, it has been shown in general terms that even a small amount of misclassification (e.g., under 5\%) could make program effects impossible to detect. ${ }^{49}$

Table 4.1 provides an indication of the extent of this problem. ${ }^{50}$ The table includes a summary of (1) implementing partner data provided to the MISTI impact evaluation team and (2) the projects that for which the MISTI impact evaluation team was able to verify location information. The data for SIKA-West provide a clear example of what could be the first type of classification error (programming villages misclassified as control villages) as the MISTI project tracker only includes 123 projects in 93 villages while the implementing partner provides data on 257 projects across 246 locations. Conversely, the data for SIKA-North provides a suggestive example of the second type of classification challenge (control villages misclassified as program villages) as the MISTI project tracker reports data on more locations that the implementing partner.

\footnotetext{
47 Though classical measurement error that is uncorrelated with the unobservables will simply cause attenuation of the point estimates (e.g., Black et al., 2003), measurement error in binary regressions is typically not classical because errors are mean-reverting (e.g., Aigner 1973, Kreider 2010). Millimet (2010) provides a review of the general challenges facing empirical analyses with measurement error in a binary regressor.

${ }^{48}$ If misclassification is severe - in that more than half of villages in the sample are misclassified - sign reversal is possible (e.g., Frazis and Lowenstein 2003) - that is, the estimate could be negative when the true program effect is positive.

${ }^{49}$ E.g., Kreider (2010).

${ }^{50}$ The MISTI impact evaluation team was working to remedy this issue at the time of writing, so the severity of this issue may have been reduced for subsequent analyses.
} 
Table 4.1: Summary Statistics for Potential Project Misclassification

\begin{tabular}{|c|c|c|c|c|c|c|}
\hline & & \multicolumn{2}{|c|}{ Implementing Partner Data } & \multicolumn{3}{|c|}{ MISTI "USAID Project Tracker" } \\
\hline & & \# Projects & $\begin{array}{c}\text { \# Villages/ } \\
\text { Implementation } \\
\text { Points }\end{array}$ & Projects & Total \# of Villages & $\begin{array}{c}\text { \# Villages in } \\
\text { Waves } 1,2 \text {, or } 3 \text { of } \\
\text { MISTI }\end{array}$ \\
\hline \multirow{5}{*}{ SIKA } & East & $230^{*}$ & $209^{*}$ & 249 & 201 & 109 \\
\hline & North & 534 & 172 & 508 & 192 & 97 \\
\hline & & & & & $--------n$ & ------1 \\
\hline & South & 413 & $2398^{\S}$ & 249 & 539 & 197 \\
\hline & West & $257^{\circ}$ & $246^{*}$ & 123 & 93 & 68 \\
\hline \multirow[b]{2}{*}{$\mathrm{CCl}$} & Creative & 725 & 475 & $\dagger$ & $\boldsymbol{t}$ & + \\
\hline & IOM & & 114 & & + & + \\
\hline \multicolumn{2}{|c|}{ KFZ } & 50 & $\ddagger$ & $t$ & $t$ & $t$ \\
\hline \multicolumn{7}{|c|}{ †: No data in project tracker provided JUL 2014.} \\
\hline \multirow{2}{*}{\multicolumn{7}{|c|}{ ¥: No data provided by implementing partners. }} \\
\hline & & & & & & \\
\hline $\begin{array}{l}\text { §: This do } \\
\text { project. }\end{array}$ & ot use the $u$ & ique locational in & ation but rather the $r$ & unts of the $n$ & er of locational points & associated with each \\
\hline
\end{tabular}

Though we are unable to precisely assess its extent, a consequence of the first type of classification is that the MISTI data contain data on relatively few villages identified as treatment villages. The longest panel of data available for the impact evaluation, which includes data from Waves 1 and 3, contains a total of 867 potential control villages and only 113 treatment villages. ${ }^{51}$ Though having excess control villages can be advantageous for the quasi-experimental matching methods, the effectiveness of these methods in producing reliable estimates for MISTI requires having sufficient numbers of both treatment and potential control villages.

The MISTI evaluation team implemented several remedial measures to address these known challenges. $^{52}$ This included project-by-project verification of locations using overhead satellite imagery, additional communication with implementing partners about project location(s), and geo-located photographs of projects being implemented. This verification process expanded the pool of verified USAID programming villages that could be included in the analysis.

However, despite these remedial efforts, there is significant uncertainty about the full range of completed, ongoing, and planned projects and the locations in which those projects were implemented. Thus, there are likely to be significant classification of the first type - i.e., villages labeled as "controls" in the data where programs are being implemented. This will lead to underestimation of program impacts.

\footnotetext{
51 This is based on the village-level data set "WAVE1-3 Data for Jay.xlsx" provides by the MISTI team. This includes all villages reported as treated by the third wave. Note that the "MISTI Wave 3" report indicates that only 108 villages are available for impact evaluation using these data (p.1).

52 These remedial measures were implemented under a separate USAID task order.
} 


\section{Implications}

Efforts to estimate the impact of development programming in conflict settings will frequently face two challenges. First, randomization will often be very hard to implement in a conflict setting, specifically in the face of guidance to "do no harm" and the reality that "randomly" providing financial resources or services to one community and not to an adjacent community in a politically fragile environment can be destabilizing. ${ }^{53}$ Second, implementing partners may also find it necessary to shift programming from a pre-planned program village to a neighbor (perhaps similar) village, whether as a result of conflict or inaccessibility. This may conflict with the equivalence of treatment and control villages — in particular, would tend to lead to more 'stable' or less remote villages in treatment group — while also complicating the identification of the treatment villages.

Best practice in the impact evaluation literature is to have close coordination between implementing partners and the evaluation team before either the evaluation or implementation begin. ${ }^{54}$ In a setting like Afghanistan, without standardized data frames, this coordination is of particular importance and perhaps the only way to address these challenges facing estimation.

Coordination should include at least three components. The first is the use of a common village map or sampling frame, and once villages are selected, clear recording of location and other identification information for program villages. Second, to support the quasi-experimental methods, the implementing partners should establish clear rules for village eligibility for projects, using measures that are clear and available for all villages. This will ensure that the researcher is able to match on the same variables that go into the determination of program eligibility. Third, the implementing partner and its subcontractors should collect detailed data on site visits to all villages, to provide more information that can be used in the matching. These can go well beyond the indicators used for determining eligibility; in general, the more information the better.

\footnotetext{
53 The author has personal experience with this phenomenon in the context of a randomized control trial in Yemen.

${ }^{54}$ As an example, see Jones et al. (2009). And USAID (2013) reports that: "Impact evaluations are always most effective when planned before implementation begins. Evaluators need time prior to implementation to identify appropriate indicators, identify a comparison group, and set baseline values. In most cases they must coordinate the selection of a treatment and comparison group with the implementing partners. If impact evaluations are not planned prior to implementation the number of potential evaluation design options is reduced, often leaving alternatives that are either more complicated or less rigorous. As a result, Missions should consider the feasibility of and need for an impact evaluation prior to and during project design."
} 


\section{Inference}

This section explores challenges facing the MISTI impact evaluation in making inference about (1) overall USAID programming executed by USAID's Afghanistan Stabilization Unit during this timeframe ("internal validity") and (2) the potential impact that similar programming would have had if executed elsewhere in Afghanistan ("external validity"). To clarify, internal validity means that the impact evaluation provides reliable estimates of program impact for the individuals or villages studied in the evaluation. External validity, in contrast, refers to the reliability of the results as a measure of program impact for the target population in general.

Omitted variable bias - namely, that one or more variables that influence the efficacy of USAID programming are excluded from the analysis - is likely the key challenge facing the internal validity of the MISTI evaluation. There are some clear steps that MISTI should take to help ameliorate this challenge, namely by expanding the range of controls included in the analysis through coordination with other actors (e.g., military, implementing partners, etc.). However, as this type of bias will always remain a concern, and particularly so in a conflict setting, the evaluation should use now well-established approaches for assessing the magnitude of this potential bias.

The key challenge to the external validity of the MISTI evaluation is the limited information on where USAID projects were implemented, discussed in Section 4. And while MISTI has taken deliberate steps to address this concern - including a very large household survey and a secondary effort to identify USAID project villages - the external validity of these findings could be enhanced through increased coordination on data with the implementing partners and matching methods to address non-random attrition in the household survey.

Reliable inference relies on high-quality data, and perhaps even more so in a conflict setting. Close coordination across implementing partners, evaluators, and other actors is important to developing results that can be used to guide future development programming. However, as these challenges are inevitable in a conflict contest, appropriately caveating the precision and generalizability of findings is essential.

\section{Internal Validity and Omitted Variable Bias}

As noted, the key challenge facing the internal validity of the MISTI results is omitted variable bias. The evaluation does include several key variables as controls in the analysis - i.e., the matching analysis includes population, elevation, dominant ethnicity, distance to district center, amount of violence in 90 days prior to aid distribution, amount of violent in 90 days after aid distribution, Wave 1 stabilization index, and density of nearby agricultural land. However, a variety of key village-level control variables (e.g., ethnic diversity, economic activity, non- 
MISTI development activity, etc.) are omitted from the analysis, which could lead to significantly biased results if these factors are correlated with program allocation. ${ }^{55}$

Non-MISTI development programming is an important example. We might expect that the current USAID programming being evaluated by MISTI (e.g., CCI, SIKA, KFZ) would be targeted toward areas that had not yet received development activity. If so, and if this development activity in control villages had been effective at enhancing stability, then this would make it appear that the MISTI-evaluated projects were performing poorly even if they might show significant improvements. Though the MISTI team did collect data on historical USAID programming conducted as part of the NSP, this represents only a small share of total USAID spending and these data were not included as controls in the empirical analysis. ${ }^{56}$

The "difference-in-difference" component of MISTI's quasi-experimental approach will attenuate the omitted variable bias problem, as long as these omitted variables change only the baseline conditions in the control communities. Omitted characteristics that themselves are changing over time - e.g., development activity by other donors is being executed in control communities simultaneously - would not be corrected for in this approach. And if omitted characteristics influenced the effectiveness of the USAID programming, this too would bias the impact estimates, since the effectiveness would not be the same in a typical village.

We recommend two courses of action to help ameliorate this concern. The first is increased coordination with other donors and U.S. government actors to help access data on variables that could be used to augment the current analysis (both to add to the list of controls to reduce the extent of missing variable problems in the analysis, and to allow for better matching in the first place as described in the last chapter) This should include additional databases of development activity (e.g., data from the Commander's Emergency Response Program managed by the U.S. military, USAID's "Afghan INFO" database) ${ }^{57}$; data on economic activity (e.g., "Nightlights", which functions as a proxy for economic activity by measuring ambient light at night from overhead satellites); ${ }^{.5}$ and data on ethnic diversity (e.g., Human Terrain Teams, ISAF polling efforts), at the very least.

The second is that MISTI should provide estimates of the likely magnitude of this potential bias. One approach, which would build from MISTI's existing matching approach, would be to use the difference between the treatment and control villages - summarized in Table 2 of USAID

\footnotetext{
55 E.g., Heckman and Robb 1985.

${ }^{56}$ For total NSP spending, see http://www.tolonews.com/en/afghanistan/10656-one-billion-dollar-invested-innational-solidarity-programme. It is important to note that subsequent MISTI reports (after Wave 3) also examined the impact of NSP programming.

57 See http://www.usaid.gov/afghanistan/performance-monitoring-plan. Note that these authors had also heard that USAID had subcontracted a firm to produce estimates of total spending at the district level.

${ }^{58}$ E.g., Henderson et al. (2012).
} 
(2014d) - in order to assess the magnitude of the potential bias attributable to omitted variables. $^{59}$

\section{External Validity}

As noted, external validity refers in the present context to the reliability of the evaluation results as a measure of program impact for the target population in general, not just in the villages in which the program was conducted. A key requirement for external validity is that the sample included in the analysis is representative of the overall population. In MISTI's case, this requires that (1) the treatment villages in the household survey are representative of the villages receiving USAID programming and (2) that the pool of treatment and control villages are representative of the villages where USAID might implement programs.

Challenges faced in the conduct of the evaluation indicate that this representativeness was not met. As discussed above, as a result of limited coordination with implementing partners, the MISTI team had incomplete information on villages receiving USAID programming. And while the MISTI household survey tried to address this problem by collecting a very large sample of villages - each wave collected more than 2,000 villages - the number of villages included across multiple surveys is more limited. This challenge is illustrated in Table 5.1. While each of the three waves of data had in excess of 2,000 villages, the villages with more than one wave of data was far fewer. "Panels" including Wave 1 - the only wave of data before program implementation - have only 800-900 villages. This "attrition" across waves was driven by the necessity to change the villages being sampled as MISTI gained additional information on where the implementing partners were actually executing projects.

${ }^{59}$ We refer the reader to Altonji et al. (2005) as one well-used approach to test for this bias. 
Table 5.1: Overlap Across Available Survey Data

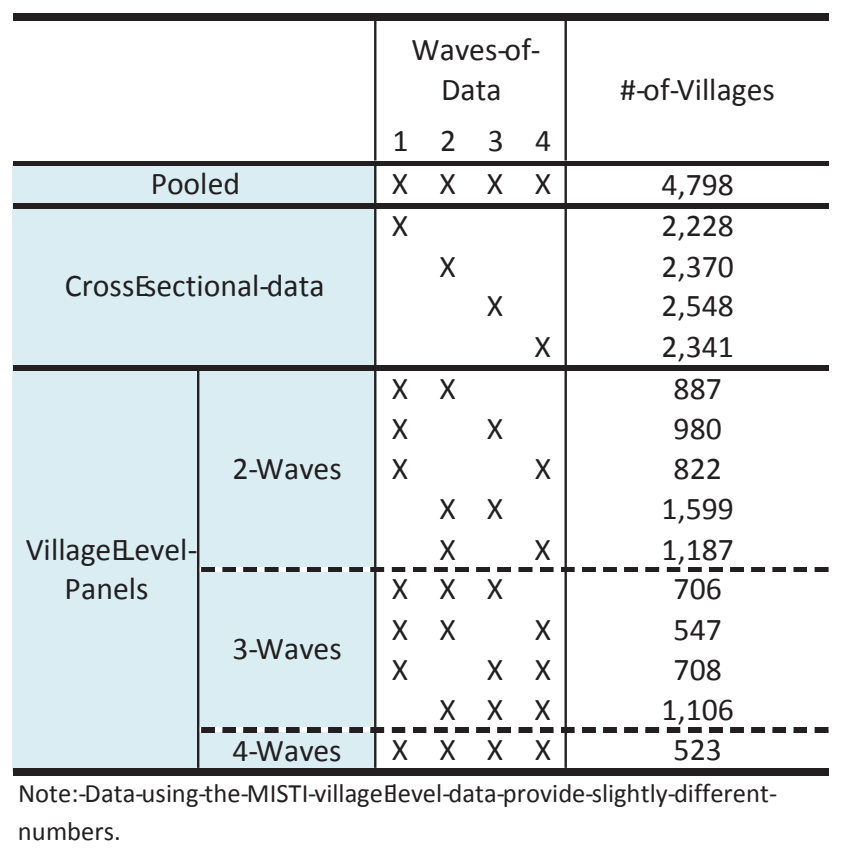

The potential loss of representativeness resulting from this attrition is analyzed in Figure 5.1, which compares the socioeconomic characteristics of villages in Wave 1 only and those that were surveyed in both Waves 1 and 3. These figures suggest that there is some loss of representativeness as a result of this attrition. While there are only limited differences in the comparison of means in the left-panel - i.e., the only significant differences across the 12 variables considered are for ethnicity (Tajik and Uzbek) and for ANSF- and Haqqani-caused casualties - the right-panel provides evidence of a significant difference between these two samples of villages. The right-panel compares the propensity score, estimated with these same 12 variables - the two propensity score curves are qualitatively different and the "balancing property" is not satisfied. ${ }^{60}$ Thus, even if the original sample of villages was representative, this analysis suggests that the panel analysis may face challenges in external validity as a result of village attrition.

We recommend two approaches to address these external validity concerns. First, in order to address the concern that the treatment villages included in the MISTI are not representative of overall USAID programming, the implementing partners should be asked to provide data on every village in which USAID programming was conducted. If sufficient detail on these villages is available, then a matching-type approach (e.g., propensity score) can be used to assess the overall selection of villages (i.e., both program and control) used in the evaluation. ${ }^{61}$ This

\footnotetext{
${ }^{60}$ E.g., Becker and Ichino (2002).

${ }^{61}$ Note that the discussion in Chapter 4 on appropriate matching of treatment (program) and control villages was concerned with the internal validity of the evaluation, which requires the two groups to be equivalent. Here we are concerned with whether the villages used in the evaluation as treatment or controls are similar to others in the
} 
process would be enhanced significantly if the MISTI team was able to coordinate with the implementing partners to identify the exact criteria that they used for selecting villages (which can be contrasted with the criteria that was used for selection villages included in the household survey).

Second, the MISTI evaluation should augment their approach to include matching algorithms to address the non-random attrition in villages within their panel - i.e., following the same intuition provided in the right-panel of Figure 5.1. Though the "balancing property" could not be satisfied using 12 key demographic variables included in the household survey, indicating that the matching was not successful, analysis including a more robust set of observables may be able to effectively adjust for this attrition.

Figure 5.1: Comparing Wave 1 to Wave $1 \& 3$ Panel

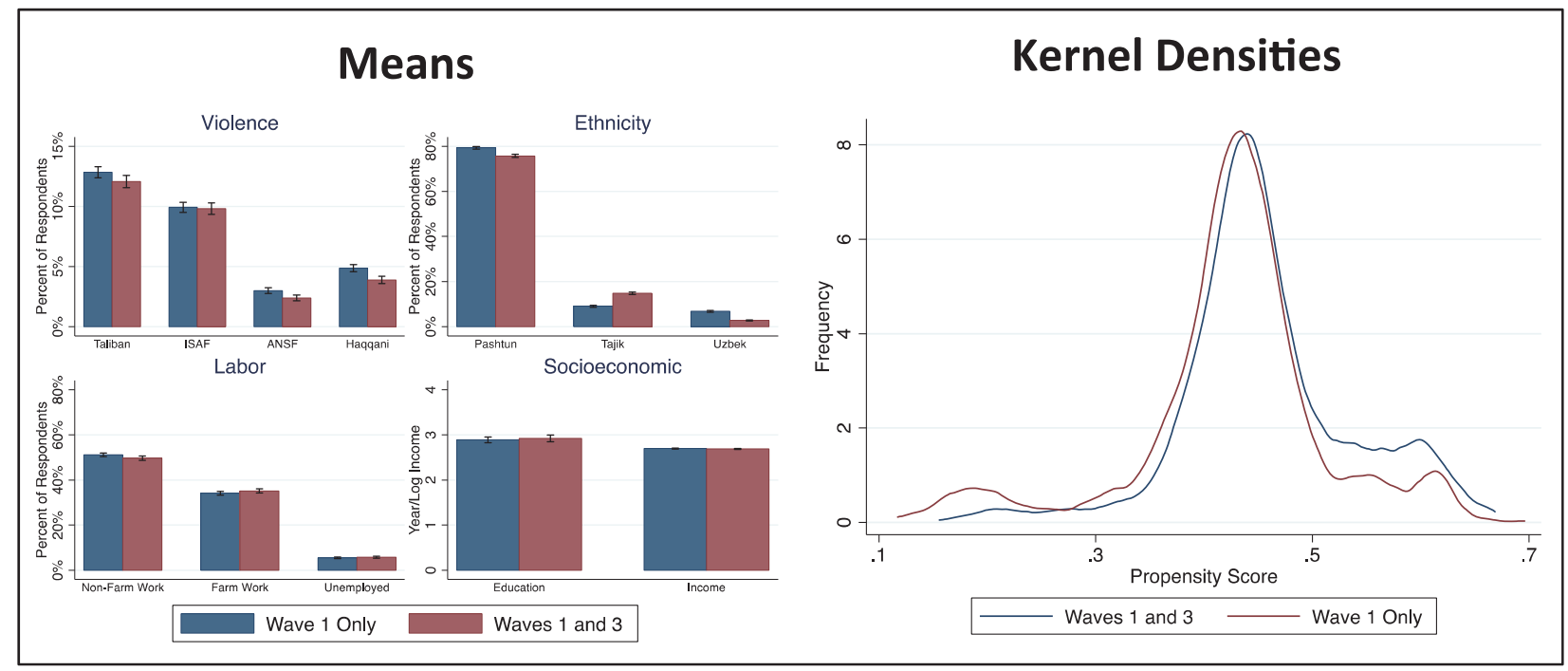

\section{Implications}

Detailed data on conditions within program and potential control villages is always important to effective evaluation. In the conflict context, where the relevance of socioeconomic and sociocultural characteristics can be exacerbated by local instability, these data can be especially expensive and hard to collect. However, finding ways to collect these data can pay dividends, as they can help address omitted variable bias concerns, and provide novel and useful insights on how pre-existing conditions (e.g., the history of development programming) influence stabilityand resiliency-focused programming.

country so that the findings on the evaluation sample are applicable more generally to the country. This is the external validity question. 
Effective coordination across both the evaluator and implementer can help ameliorate some data concerns. However, as data limitations are inevitable, appropriately caveating results and being cautious about the generalizability of findings is recommended. 


\section{Implications for MISTI and Assessment in Conflict Settings}

This final section reviews the preceding sections to highlight the key lessons learned from our review. The discussion is divided into three parts. The first provides a set of recommendations that the MISTI impact evaluation can implement in producing their Waves 4 and 5 reports, as well as ancillary impact evaluations. These steps can also be applied in a reanalysis of the earlier reports. Note that the MISTI impact evaluation team has already or is planning to implement several of these recommendations. ${ }^{62}$ The second part discusses steps that that USAID and MISTI could have undertaken at the outset of the program to ensure a more robust evaluation - and that should be considered for future programming. The third part describes challenges that will always be outside the control of the evaluator, but things that future impact evaluations conducted in conflict areas should be aware of. We conclude by offering some general thoughts about the implications of this review for future USAID impact evaluations in conflict settings.

\section{Recommendations for Improving MISTI Waves 4 and 5 Reports}

1. Assess severity of treatment/control misspecification: At this late stage in the game, project-by-project verification of the location of each project that was either planned or implemented is likely to be infeasible. However, a potential simple and low cost way to assess the severity of misspecification is to add additional questions to the village-level module to the survey data collection in Wave 5. Specifically, while the survey teams are in the village, the team lead can meet with both village and district officials to determine which villages that implementing partners had visited. ${ }^{63}$ This will not allow the impact evaluation team to expand the number of treated villages included in the sample, but it will allow a clear assessment of the severity of misspecification. These data could be combined with MISTI's ongoing treatment village data clarification to allow a reclassification of treatment and control village categorization that can be used to reanalyze the earlier waves' data as well as the data going forward.

2. Include several different "matching" estimators: MISTI's quasi-experimental approach relied on a single class of matching estimators - namely, those that require exact

\footnotetext{
${ }^{62}$ We note that some of these suggestions have already been implemented in the Wave 4 and Wave 5 reports, though we have not reviewed these documents.

${ }^{63}$ The MISTI evaluation team has suggested that this approach may not yield useful responses at the village-level, as village leaders or officials are unlikely to have visibility on development programming.
} 
matching on covariates. ${ }^{64}$ As different classes of matching estimators have different strengths and weaknesses, the evaluation should include a variety of different matching estimators to verify the robustness of their findings (e.g., Imbens 2004) - the results from each of the different classes of estimators should be provide in the main report. ${ }^{65}$

3. Work with implementing partners to identify how villages were selected for program participation. The effectiveness of quasi-experimental methods - which essentially involve choosing appropriate, i.e., similar, controls for the treated units - can be enhanced by a clear understanding of how and why villages were selected for participation in one of the USAID programming. Indeed, the implementing partners should have collected data as part of their "sources of instability" assessment for each of these villages. These discussions and assessments would both provide material for the MISTI impact evaluation team to justify their empirical specification for the quasiexperimental methods. Additionally, the research team may learn of other important factors that should be included in the matching; given the richness of the household survey data collected, it should be possible to augment their existing approach with most if not all of these additional factors. ${ }^{66}$

4. Include expanded data on development programming: Both MISTI and USAID should make use of all available data on historical development programming in the areas used for the analysis. This should include MRRD, which is publicly available and includes data on both the NSP program (which is already included in the analysis) and other development programming; unclassified data on the Commander's Emergency Response Program, which USAID should be able to request from the Department of Defense; as well as the diverse range of USAID collected data on program implementation. These data should be used both to improve the matching of treatment and control villages and in the actual estimation of impacts as control variables. Further, in addition to simply including the number of projects implemented in an area, the research team should include additional project-specific variables such as total resources allocated (e.g., Berman et al. 2011).

5. Use data-driven methods for developing and testing the stability index. The need to use some kind of stability index is understandable given the objectives of the evaluation. However, the approach currently used is problematic and yields an index that is hard to

\footnotetext{
${ }^{64}$ As noted earlier, they do include two different types of estimators, but they are both from the same class of matching estimators and thus both suffer from the same limitations.

${ }^{65}$ The MISTI impact evaluation team has indicated in private correspondence that they have implemented some propensity score methods; however, the results are not presented in available reports.

${ }^{66}$ The MISTI impact evaluation team has indicated that they have made significant effort to engage with implementing partners; however, they indicated that the implementing partners have been unable to produce any documented record of the results from the "sources of instability" assessment.
} 
interpret, both because of the disparate elements included and the arbitrary weighting of these elements. The impact evaluation team should use factor analytical methods for developing a more meaningful measure of overall stability. ${ }^{67}$

6. Analyze individual components of stability separately: Given the concerns about the disparate elements of the stability index at least as currently constituted, rather than focusing on a single stability index for the impact evaluation, the researchers should consider various components separately. Since there are so many individual components grouping them into sub-indices along clear subject lines would be recommended.

Alternatively, exploratory factor analysis could be used to pull out different components of stability. ${ }^{68}$

7. Validate the stability measure using ancillary data from 2012-2013: Given the historically available data, the evaluation team should conduct validation exercises using historical polling data and violence data. If the index does indeed measure stability, then the likelihood of violence should be higher in areas that were judged to be less stable using the index.

8. Coordinate with ISAF and other representatives to validate the stability metric: Given the diversity of U.S. Government organizations involved in assessing instability, the MISTI team should make a robust effort to engage with relevant ISAF officials (e.g., Afghan Assessment Group) in order to discuss, validate, and have their approach reviewed. Assessing the relationship between the MISTI and ISAF data, and identifying any discrepancies, could help provide additional confidence in both the overall index as well as the 42 independence variables.

9. Match projects to intended outcomes: Rather than focus on only the reduced form outcomes currently considered - i.e., from program inputs to stability - the analysis should also validate whether the program is having the intended immediate impact (e.g., improved district governance) as well. ${ }^{69}$ Indeed, even if the evidence indicates that USAID programming is enhancing stability, understanding the meaning of those results is impossible without an understanding of whether the programs are achieving their intended development outcomes. Indeed, while the main focus of USAID for this evaluation is on stability, a more logical and sound evaluation approach would be to use the rich survey data for impact evaluations of the programs on the outcomes which they are intended to influence directly, and then proceed to estimating impacts on stability.

\footnotetext{
${ }^{67}$ E.g., Bohrenstedt (2010).

${ }^{68}$ As an example, a principal component analysis conducted by the MISTI team suggests that the government confidence and community resiliency should be divided into three separate sub-indices for analysis, and that the overall stability index may need to be divided into as many as nine different indices (MSI 2014).

${ }^{69}$ A model paper for this is Casey, Glennerster, and Miguel (2012).
} 


\section{Things that Could Have Been Done and Should be Done for Future Evaluations}

1. Coordinate with implementing partners from the onset: Close coordination between Implementing partners and evaluation teams is a standard practice now in the impact evaluation literature, and it is of particular importance in developing countries. The main benefit to such a process for MISTI would have been a clearer understanding of where the interventions took place. Given that this coordination typically requires additional human resources cost for the Implementing partners themselves, as they have to attend additional meetings and may need to hire survey specialists to collect or interpret specialized data (e.g., location data) both USAID and MISTI would have to been involved in this type of coordination as well as be willing to support it financially. While MISTI themselves could not have done this, USAID could have modified existing contracts with the implementing partners and provided MISTI-specific resources to the implementing partners to support this effort. It may be noted that while additional resources would be necessary for this, they would likely be a trivial fraction of the total allocated to the evaluation, and have very high returns in terms of the quality of the evaluation.

2. Stratify based on previous development programming: Given the likelihood that previous development programming could influence the outcomes of the current USAID programming being implemented, USAID should have coordinated to access all available databases on historical development programming and included in the sampling strategy to allow for stratification. Importantly, as the MISTI impact evaluation team indicated that they made substantial efforts to do this at project inception but faced significant difficulties, this process may require USAID-led coordination with other U.S. government foreign government, and international agencies.

3. Cleary articulate theory of change at program commencement. Researchers together with USAID and program developers should articulate a clear theory of change linking the program activities to outcomes and impacts before program commencement. The theory of change would describe how the direct impacts of the programs would lead to improved stability.

\section{Challenges outside MISTI/USAID Control}

1. Quality of data on historical development programming: Existing data on development programming does include information on project success, and faces challenges in terms of accuracy of resources allocated and the specific location of where projects were implemented. Though all these factors will increase the measurement error associated with these data, there is no reasonable way that MISTI could have addressed this. 
2. Implementing partner heterogeneity: Implementing programs in highly heterogeneous and conflict-prone settings will often require coordination with a diverse set of implementing partners. While controls can be put in place to try to assess how this affects program implementation and its likely effects, assessing program effects given this heterogeneous treatment can be complicated.

3. External validity of the analysis: Development programming in Afghanistan typically requires targeting the programs to areas that are more receptive to development programs, and successful development programming requires tailoring the programs to local conditions and cultures. Further, it goes without saying that the situation in Afghanistan is unique so that results may not be easily generalized to other conflict settings - though the same can be said of any development related evaluation. As such, while the analysis from MISTI is useful in that it establishes a useful framework for conducting future impact evaluations, the results from this analysis are not necessarily relevant for other potential development programs within Afghanistan or in other conflict-prone contexts.

\section{Implications for Future USAID Impact Evaluations}

Understanding the effectiveness of interventions in the midst of active conflict is essential to the development of effective policies to address both the causes and consequences of this conflict. As illustrated in the MISTI experience, active conflicts and highly unstable environments create core challenges that impede impact evaluation, particularly when evaluators are asked to assess difficult to measure outcomes like "stability" in a national-level program with multiple implementing partners.

If the intent is to understand the impact of a specific suite of programming on stability, future USAID impact evaluations should consider employing more rigorous evaluation approaches applied on a small set of projects. ${ }^{70}$ However, if the intent is rather to assess whether large-scale programming is achieving its intended objectives, evaluations should first focus on assessing whether direct effects are achieved before attempting to measure more elusive outcomes like stability.

${ }^{70}$ E.g., Duflo, Glennerster, and Kremer (2008). 


\section{References}

Abadie, A., D. Drukker, J. L. Herr, and G. W. Imbens. 2004. Implementing matching estimators for average treatment effects in Stata. Stata Journal 4(3): 290-311.

Abadie, A. and Imbens, G. (2006) Large sample properties of matching estimators for average treatment effects. Econometrica 74(1): 235-267.

Aigner, D.J. (1973), "Regression with a Binary Independent Variable Subject to Errors of Observation," Journal of Econometrics, 1, 49-60.

Altonji, Joseph G., Todd E. Elder, and Christopher R. Taber (2005), "Selection on Observed and Unobserved Variables: Assessing the Effectiveness of Catholic Schools," Journal of Political Economy, 113:1.

Becker, Sascha and Andrea Ichino (2002), "Estimation of Average Treatment Effects Based on Propensity Scores", The Stata Journal, 2(4), 358-377.

Berman, Eli, Jacob N. Shapiro and Joseph H. Felter. "Can Hearts and Minds Be Bought? The Economics of Counterinsurgency in Iraq” Journal of Political Economy, August 2011.

Black, D., S. Sanders, and L. Taylor (2003), "Measurement of Higher Education in the Census and Current Population Survey", Journal of the American Statistical Association, 98, 545554.

Blackwell, Matthew \& Stefano Iacus \& Gary King \& Giuseppe Porro, 2009. "cem: Coarsened exact matching in Stata," Stata Journal, StataCorp LP, vol. 9(4), pages 524-546, December.

Bohrnstedt, G. (2010). Measurement models for survey research. In P. V. Marsden 8: J. D. Wright (Eds.), Handbook of survey research (2nd ed., pp. 347-404).

Casey, Katherine, Rachel Glennerster, and Edward Miguel (2012). "Reshaping Institutions: Evidence on Aid Impacts Using a Preanalysis Plan”, Quarterly Journal of Economics, 127(4, December 2012): 17551812.

Cragin, R. Kim (2014). Resisting Violent Extremism: A Conceptual Model for NonRadicalization. Terrorism and Political Violence. Vol. 26, Iss. 2, 2014.

Duflo, Esther, Rachel Glennerster, and Michael Kremer. 2008. "Using Randomization in Development Economics Research: A Toolkit." In Handbook of Development Economics, Volume 4, ed. T. Paul Schultz and John Strauss, 3895-3962. Amsterdam and Oxford: Elsevier, North-Holland. 
Duflo, E. and M. Kremer (2005) "Use of randomization in the evaluation of development effectiveness" in G. Pitman, O. Feinstein, G. Ingram (Eds.), Evaluating Development Effectiveness, Transaction Publishers, New Brunswick, NJ (2005)

Frazis, H. and M.A. Loewenstein (2003), "Estimating Linear Regressions with Mismeasured, Possibly Endogenous, Binary Explanatory Variables", Journal of Econometrics, 117, 151178.

Greene, William H. (2011). “Econometric Analysis”, Prentice Hall, $7^{\text {th }}$ Edition.

Heckman, J. and R. Robb (1985). "Alternative methods for evaluating the impact of interventions: an overview." Journal of Econometrics, 30 (1,2) (1985), pp. 239-267

Henderson, V. J., A. Storeygard, and D. N. Weil (2012): "Measuring Economic Growth From Outer Space," American Economic Review, 102 (2), 994-1028.

Hirano, K., G. W. Imbens, and G. Ridder (2003, July). Efficient estimation of average treatment effects using the estimated propensity score. Econometrica 71 (4), 1161-1189.

Imbens, G. (2004): "Nonparametric Estimation of Average Treatment Effects under Exogeneity: A Survey," Review of Economics and Statistics, 86, 4-30.

Jones, N., Jones, H., Steer, L. and Datta, A. (2009) "Improving Impact Evaluation Production and Use.” Working Paper 300. London: ODI.

Kreider, B. (2010). "Regression coefficient identification decay in the presence of infrequent classification errors", Review of Economics and Statistics, 92 (4) (2010), pp. 1017-1023.

Lyall, Jason, Graeme Blair, and Kosuke Imai, "Measuring Support for Combatants in Wartime: A Survey Experiment in Afghanistan," American Political Science Review (August 2013).

Management Systems International (2014). "Review of Stability Indices", mimeo.

Millimet, D., 2010. The elephant in the corner: a cautionary tale about measurement error in treatment effects models, Southern Methodist University and IZA Discussion Paper No. 5140 .

Pande, Rohini and Chris Udry (2005). "Institutions and Development: A View from Below," in Proceedings of the 9th World Congress of the Econometric Society, edited by R.Blundell, W.Newey and T.Persson, Cambridge University Press, 2005.

Ridgeway, G., D. McCaffrey, A. Morral, B.A. Griffin, and L.F. Burgette (2012). twang: Toolkit for weighting and analysis of nonequivalent groups.

Robins, J. M., A. Rotnitzky, and L. P. Zhao (1994). Estimation of regression coefficients when some regressors are not always observed. Journal of the American Statistical Association 89. 
Special Inspector General for Afghanistan Reconstruction [SIGAR] (2015). "Quarterly Report to the United States Congress", July 30, 2015.

USAID (2013a). "USAID Stabilization Unit Afghanistan: Performance Management Plan, Fiscal Years 2012-15", June 18, 2013.

USAID (2013), “Technical note in impact evaluation.” September 2013.

USAID (2014a). "Stability in Key Areas - West: Mid-term Performance Evaluation", 26 March 2014.

USAID (2014b). "USAID Stabilization Unit Afghanistan: Performance Management Plan Update, Fiscal Years 2012-15”, May 2014.

USAID (2014c). "MISTI Stabilization Trends and Impact Evaluation Survey Analytical Report, Wave 2: MAY 18 - AUGUST 7, 2013”, March 42014.

USAID (2014d). "MISTI Stabilization Trends and Impact Evaluation Survey Analytical Report, Wave 3: NOV 16, 2013 - JAN 30, 2014”, July 42014.

White, Howard (2013). "An Introduction to the Use of Randomized Control Trials to Evaluate Development Interventions", International Initiative for Impact Evaluation (3ie) Working Paper 9 (http://www.3ieimpact.org/media/filer_public/2013/01/15/working_paper_9.pdf). 